University of South Florida

DIGITAL COMMONS

Digital Commons @ University of

@ UNIVERSITY OF SOUTH FLORIDA

South Florida

$11-5-2015$

\title{
Is Nubia Plate Rigid? A Geodetic Study of the Relative Motion of Different Cratonic Areas within Africa.
}

\author{
Mary Wambui Njoroge \\ University of South Florida, mnjoroge@mail.usf.edu
}

Follow this and additional works at: https://digitalcommons.usf.edu/etd

Part of the Geographic Information Sciences Commons, and the Geology Commons

\section{Scholar Commons Citation}

Njoroge, Mary Wambui, "Is Nubia Plate Rigid? A Geodetic Study of the Relative Motion of Different Cratonic Areas within Africa." (2015). USF Tampa Graduate Theses and Dissertations.

https://digitalcommons.usf.edu/etd/6003

This Thesis is brought to you for free and open access by the USF Graduate Theses and Dissertations at Digital Commons @ University of South Florida. It has been accepted for inclusion in USF Tampa Graduate Theses and Dissertations by an authorized administrator of Digital Commons @ University of South Florida. For more information, please contact digitalcommons@usf.edu. 
Is Nubia Plate Rigid? A Geodetic Study of the Relative Motion of Different Cratonic Areas within Africa

by

\author{
Mary Wambui Njoroge
}

A thesis submitted in partial fulfillment of the requirements for the degree of

Master of Science School of Geosciences with a concentration in Geology College of Arts and Sciences University of South Florida

\author{
Major Professor: Rocco Malservisi, Ph.D. \\ Timothy Dixon, Ph.D. \\ Urs Hugentobler, Ph.D.
}

Date of Approval:

November 3, 2015

Keywords: Euler vectors; Reference frame; Rate residual; Internal deformation. Copyright ( ) 2015, Mary Wambui Njoroge. 


\section{ACKNOWLEDGMENTS}

First I would like to thank my dear parents for their constant moral and financial support throughout my studies. Thanks to my siblings for being there for me, they gave me a shoulder to lean on in time of need. Their motivation is highly appreciated.

Many thanks to Dr. Rocco Malservisi; my advisor for his persistent encouragement, financial support, and guidance in this study. I appreciate his efforts towards helping me join graduate school in USF, and adapting to the new culture and education system. His concern about furthering my career by introducing me to other Geoscientists cannot go unmentioned.

I would like to express my gratitude to Prof. Tim Dixon and Dr. Rocco Malservisi for providing with equipment and supplies in Geodesy lab, which where major necessities in my research. I am glad to my previous advisors (at the International Center for theoretical Physics-ICTP) Dr. Mariangela Guidarelli for introducing me to Solid Earth Studies and Research. Not forgetting Dr. Fred Kucharski and Dr. Riccardo Farneti (Oceanography professors') and Dr. Andrian Tompkins ( Atmospheric Physics professor) from whom I appreciate the relationship between three (Solid Earth, oceans and atmosphere) major components of Earth system.

I take this opportunity to appreciate all graduate students for their willingness to exchange ideas. They also made my life in USF enjoyable by organizing socializing events. 
Finally, I thank my Thesis committee members; Dr. Rocco Malservisi, Prof. Timothy Dixon, and Dr. Urs Hugentobler for their invaluable input, discussion and time spend towards this study. 


\section{TABLE OF CONTENTS}

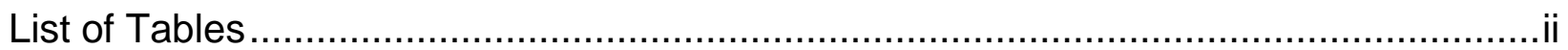

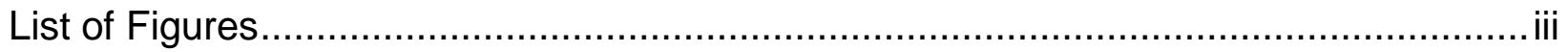

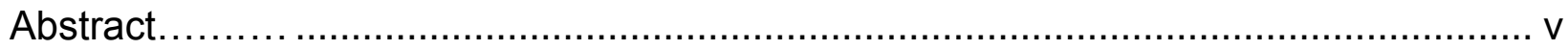

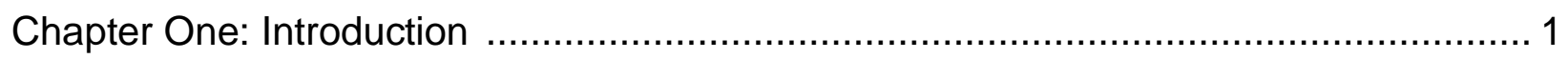

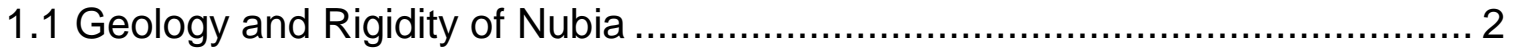

1.2 Rigid Plate Motion and Euler Vectors ................................................... 4

1.3 Previous Africa Plate Kinematics Models ............................................. 5

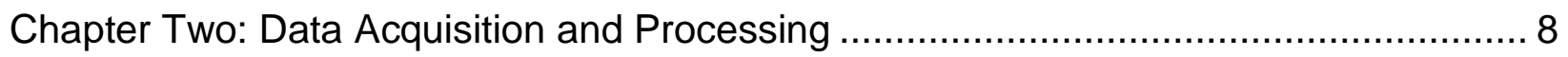

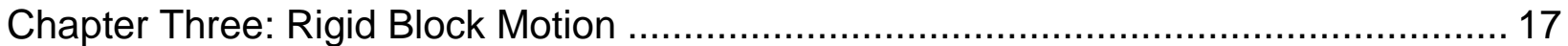

3.1 West Region Euler Vector ............................................................. 20

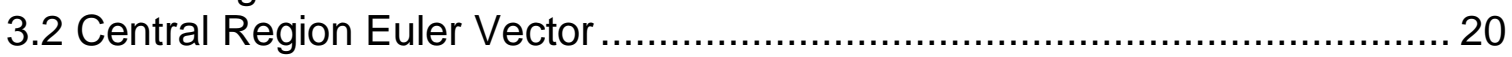

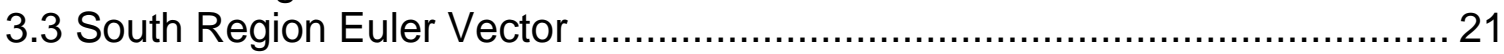

3.4 Combined Euler Vectors ................................................................... 22

3.5 West-Central Region Euler Vector.................................................... 22

3.6 South-Central Region Euler Vector .............................................. 22

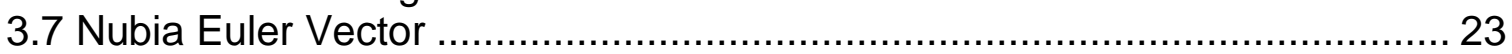

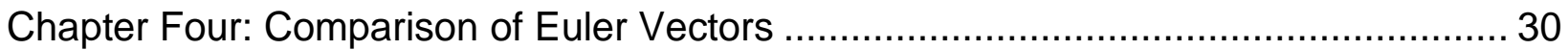

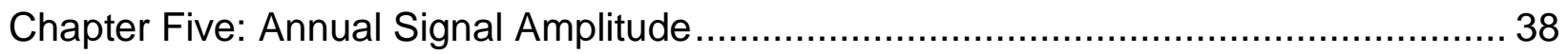

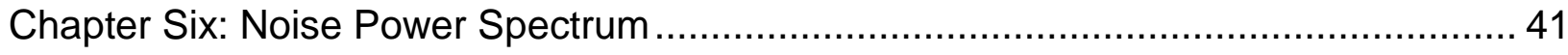

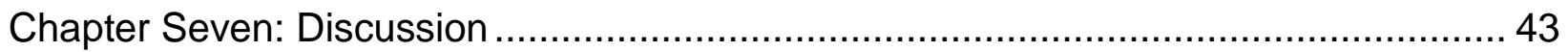

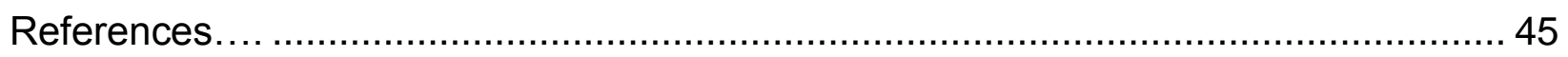

Appendix 1: Mathematical Formulation for the Inverse Problem to Find the Best Fitted Euler Vector. 


\section{LIST OF TABLES}

Table 1: GPS Data Used for Computation of Euler Vectors for Nubia Cratons ............. 13

Table 2: Region Euler Vectors with Respect to IGb08 in Geographic Coordinates ....... 24

Table 3: Region Cartesian Components and Covariance Matrix of Euler Vectors ........ 24 


\section{LIST OF FIGURES}

Figure 1: A map of Africa showing the Nubia (NU) and Somalia (SO) plates and the three microplates: Victoria Plate (VP), Rovuma Plate (RP), and Lwandle Plate (LP)

Figure 2: The vertical (Vert) and horizontal (E-W and N-S) time series of ANTH station

Figure 3: The vertical (Vert) and horizontal (E-W and N-S) time series of BFTN station

Figure 4: Residuals with respect to the motion described by the Euler vector that minimize the velocity of the red triangles for the three main regions (top to bottom: West, Central, and South)

Figure 5: The velocity field of West (W), Central (C), and South (S) regions (from top to bottom), with respect to Euler vectors calculated for Figure 4 (from left to right: West, Central and South Euler poles)

Figure 6: The velocity fields of West, Central and (from top to bottom), with respect to Euler poles South WEST_C, SOUTH_C and NUBIA (from left to right)

Figure 7: The velocity fields of West-Central (WC), South-Central (SC) and Nubia (NU) (from top to bottom), with respect to WEST, CENTRAL and SOUTH Euler poles (left to right).....

Figure 8: The velocity fields of West-Central, South-Central and Nubia (top to bottom), with respect to WEST_C, SOUTH_C and NUBIA Euler poles

Figure 9: Positions and $2 \sigma$ error ellipses (95\% confidence) of the six Euler poles: WEST (blue), CENTRAL (green), WEST_C(cyan), SOUTH_C (magenta), SOUTH (red), and NUBIA (black) in 2-dimensions, calculated with respect to the IGb08 reference frame 
Figure 10: Error ellipsoids (95\% confidence) of the six Euler vectors: WEST (yellow), CENTRAL (red), WEST_C (cyan), SOUTH_C (magenta), SOUTH (blue), and NUBIA (green) in 3-dimensions, calculated with respect to the IGb08 reference frame

Figure 11:Positions and $2 \sigma$ error ellipses (68\% confidence) of the six Euler poles: WEST (blue), CENTRAL (green), WEST_C(cyan), SOUTH_C (magenta), SOUTH (red) and NUBIA (black) in 2-dimensions, calculated with respect to the IGb08 reference frame

Figure 12: Error ellipsoids (68\% confidence) of six Euler vectors: WEST (yellow), CENTRAL (red), WEST_C (cyan), SOUTH_C (magenta), SOUTH (blue), and NUBIA (green) in three dimensions, calculated with respect to the IGb08 reference frame

Figure 13: Positions and $2 \sigma$ error ellipses (95\% confidence) of the four Euler poles; Altamimi et al., 2007 (green), Nocquet et al., 2006 (blue), Stamps et al., 2008 (red) and this study (black), calculated with respect to ITRF and IGb08 reference frames.

Figure 14: The error ellipsoids (95\% confidence) of the four Euler poles; Altamimi et al., (2007), Nocquet et al., (2006), Stamps et al., (2008) and this study, calculated with respect to ITRF and IGb08 reference frames 37

Figure 15: Signal amplitudes of the vertical GPS components of the Nubia plate. 40 


\begin{abstract}
The Nubia plate is normally considered to be a rigid plate and as such used in the realization of terrestrial reference frame. Gondwana breakup plate reconstruction, the Cameroon volcanic line, seismicity, and the morphology of the Okavango rift zone (ORZ) suggest the presence of internal deformation within the Nubia plate. To test this hypothesis, six different reference frames were developed from the velocity field of three individual regions (West, Central and South), and of different combinations of them (West+Central, South+Central, and Nubia as a whole). The residual velocities with respect to these references frame help us understand the presence of the relative motion between the different regions thus the stability of the plate.

To realize the reference frames, all the publicly available global positioning system (GPS) data within the "stable" Nubia plate was processed. Given the small relative velocity, it is important to eliminate eventual biases in the analysis and to have good estimates of uncertainty of the observed velocities. For this reason, velocities were analyzed, and rate uncertainties computed using the Allan variance of rate (AVR) technique, accounting for colored noise.
\end{abstract}

Although geological and geophysical studies indicate the possibility of internal deformation within Nubia, the results of this study shows that the current GPS network is not capable to identify intraplate deformation and within uncertainties Nubia is a single plate. As final note, both the color of the noise and the amplitude of the annual signal of 
each time series as function of latitude and climatic region were analyzed. The study shows that the noise is approximately flicker for all the good stations independently of the location. On the contrary, the amplitude of the annual signal is strongly dependent on the climate of the regions. 


\section{CHAPTER ONE: INTRODUCTION}

Plate rigidity is one of the main paradigms of plate tectonics and is a fundamental assumption in studying plate tectonics or geodynamics (Chase, 1972) as well as in the definition of a global reference frame such as International terrestrial reference frame, ITRF (e.g. Altamimi et al., 2002, 2007, 2011). The determination of the rigidity of a plate is thus a key point in understanding the limit of this assumption and how much it could affect our interpretations. Different studies have previously utilized geodetic data in order to quantify the rigidity (or lack of rigidity) of different plates (e.g. Chase, 1976; Argus and Gordon, 1996; Dixon et al., 1996; Sella et al., 2002; Malservisi et al., 2013), the rigidity of blocks or microplate (e.g. Fernandes et al., 2013; Plattner et al., 2007; Weber et al., 2010) or the relative motion between rigid microplates (e.g. Cretaux et al., 1998; Sella et al., 2002; Kreemer et al., 2003; Fernandes et al., 2004; Prawirodirdjo and Bock, 2004; Calais et al., 2003; Nocquet et al., 2006; Argus et al., 2010; Altamimi et al., 2012; Saria et al., $2013,2014)$. Although still far from optimal, the recent increase in GPS instrumentation within the African region, allows us to better understand how good rigidity assumption for the Nubia plate is. In addition to the rigidity study, the location of the African geodetic network within a tectonically stable and climatically dry regions such as the Kaapvaal craton (De Wit et al., 1992) can provide important information about the limitations of GPS as a tool to evaluate plate rigidity. 


\subsection{Geology and Rigidity of Nubia}

The Nubia plate corresponds to the western and largest part of Africa. It formed from the division of the African plate along the continental East African Rift System (EARS), which began in the early Miocene. Nubia is bordered by four extensional boundaries on the east, northeast, west, and south, and one compressional boundary in the northwest (Stein et al., 1984; Ebinger 1989; Jestin et al., 1994; Chu and Gordon, 1999; Cretaux et al., 1998 ; Hartnady, 1990, 2002; Kreemer et al., 2003; Sella et al., 2002; McClusky et al., 2003; Nocquet and Calais, 2003; Fernandes et al., 2004; Chorowicz et al., 2005; Nocquet et al., 2006; Horner-Johnson et al., 2007; Stamps et al., 2008; Delvaux and Barth 2009; Saria et al., 2014). Within the plate, the continental part is primarily composed of large cratonic regions, indicating a low degree of recent tectonic activity (Krabbendam and Barw, 2000). The Nubia plate and its counterpart, the Somalia plate on the east side of EARS (McKenzie et al., 1970), are linked together by three microplates: Victoria, Rovuma, and Lwandle (Figure 1) which are separated by well-defined divergent boundaries (the different branches of EARS) (Nusbaum et al., 1993; Hartnady, 2002, Roberts et al., 2012; Calais et al., 2006; Stamps et al., 2008; Saria et al., 2013). The main body of the Nubia plate consists of three Archean cratonic regions (West African, Congo, and South African Kalahari) (Begg et al., 2009). These cratons are mainly composed of 3.6-2.5 Ga igneous and metamorphic rocks (Begg et al., 2009; Cahen et al.,1984; Condie,1994) with lithospheric mantle thickness greater than $300 \mathrm{~km}$. The cratons are separated by old sutures of possibly weaker lithosphere (Hartnady, 1990; Begg et al., 2009; Black and Liegeois, 1993, Krabbendam and Barw, 2000). Different plate 
reconstructions indicate that during the breakup of Gondwana, the Nubia plate has been subject to internal deformation mainly along the suture zone between the cratons (Black and Liegeois, 1993; Hoffman, 1999; Reeves et al., 1999; Reeves and De Wit 2000; De Wit et al., 2008; Reeves et al., 2004; Eagles, 2007; Nemčok et al., 2012). Observed seismicity, geomorphology, and geophysical data suggest that there is tectonic activity along the Cameroon volcanic line (the region separating West Africa and Congo cratons and a hot spot track) and along the southwest propagation of the East African Rift System (swEARS) along the Okavango river delta (Graham and Brandt, 2000; Nusbaum et al., 1993; Midzi et al., 1999; Hartnady, 1990; Nyblade and Langston, 1995; Modisi 2000; Hartnady, 2002, Shemang and Molwalefhe, 2011). It is thus possible that we are observing intraplate deformation within the "rigid" Nubia plate or that the "rigid" Nubia plate is in reality divided in at list 3 major blocks. In other words that the rigidity assumption for the Nubia plate is not completely supported. Previous geodetic studies suggest that internal tectonic deformation within the Nubia plate is $\leq 0.6 \mathrm{~mm} / \mathrm{yr}$ and is possibly located along the swEARS (Deprez et al., 2013; Malservisi et al., 2013; Saria et al., 2013). However, the uncertainties are significant (larger than the value itself) and the location of deformation is not well constrained. Therefore, this study aims at improving the quantification and location of possible Nubia's internal deformation through the use of longer time series and enhanced uncertainty analysis. The study shows that although the current network configuration and associated uncertainties do not unequivocally indicate that Nubia plate is rigid, the data are compatible with rigid plate motion. 


\subsection{Rigid Plate Motion and Euler Vectors}

The motion of a rigid body on a sphere can always be described as a rotation around an axis call Eulerian axis (Goldstein, 1950; McKenzie and Parker, 1967; Le Pichon, 1968; Morgan, 1968), it is always possible to define a rigid plate reference frame looking for the Eulerian axis that better describe the observed motion of a subset of geodetic stations (Minster et al., 1974). The departure from the rigid plate motion (residual), give the relative motion with respect to a reference, being it motion of a rigid block or internal deformation. Practically, in the case that geological evidences suggest that the observed stations are all within a rigid block, the residual velocities are a critical test on the rigidity of the observed reference (Plattner et al., 2007; Sella et al., 2002, 2007). One of the largest problems in studying plate rigidity through satellite geodesy, has been that we need to deal with velocities of the order of 1 to $2 \mathrm{~mm} / \mathrm{yr}$, not significantly larger than the geodetic measurement uncertainties (Gordon, 1998; Plattner et al., 2007). The problems are also amplified when we need to deal with sparse geodetic networks, as it is often the case for the stable plate interior and in particular in Africa. In this case, the validation of the results about plate rigidity deals with small samples statistics (Stein and Gordon, 1984).

Traditionally the location of the Euler vector has been determined studying relative motion of two plates using the direction of transform faults or ridges between the two. Similarly, the rate has been inferred by spreading rate through the use of magnetic anomalies (e.g. McKenzie and Parker, 1967; Morgan, 1968; McKenzie and Sclater, 1971; Pitman and Talwani, 1972; DeMets et al., 1990). More recently geodetic data can be utilized to infer the motion of a plate with respect to a given reference frame and describe this motion 
with Eulerian vectors (e.g. Argus and Gordon, 1996; Dixon et al., 1996; Malservisi et al., 2012; Plattner et al., 2007).

Here I utilize the velocity field of geodetic sites within the "rigid" Nubia plate to derive the Euler vector describing the motion of the full Nubia plate with respect to the ITRF (Altamimi et al., 2011) and analyze the residuals looking for potential internal deformation. Furthermore, I will derive the Euler vectors for 3 different subsets of data corresponding to geodetic point within the 3 major cratonic areas. A comparison of the different Euler vectors provides a test for possible relative motion of the 3 blocks. We expect that if West, Central, and Southern Africa do not present relative motion, the three Euler vectors describing the motion should overlap within uncertainties.

The mathematical formulation for the Euler vector is described in the Appendix 1.

\subsection{Previous Africa Plate Kinematic Models}

Although McKenzie et al., (1970) had determined relative motion between Nubia and Somalia plates from the opening of Red sea and Gulf of Aden, until mid 1990s (Jestin et al., 1994; ), the two plates has been considered as a single entity (Africa plate) in many studies (Chase,1978; Minster and Jordan, 1978; DeMets et al., 1990). This is due to the fact that for a long time kinematic constrains were not sufficient to resolve the relative motion of the two plates (Hartnady et al., 2002). With increased data as the rates of seafloor spreading, marine magnetic profiles and azimuths of transform faults Jestin et al., (1994) demonstrated the presence of significant differences between Nubia-Arabia and Somalia-Arabia motion. Chu and Gordon, (1999), used plate circuit and ocean spreading data to illustrate that Nubia-Antartica and Somalia-Antartica motion were significantly 
different, hence Nubia and Somalia are separate plates. Lameux et al., (2002) used the location of magnetic anomaly 5 (> $11 \mathrm{~m} . \mathrm{y}$ ago) to determine the position of the NubiaSomalia plate boundary along the Southwest Indian Ridge. Horner-Johnson et al., (2005) used both rates of sea-floor spreading and transform faults orientation to study the relative motion between Nubia and Somalia plates.

Space geodetic data have been used for the last 2.5 decades to study the relative motion between the two plates (Cretaux et al., 1998; Sella et al., 2002; Kreemer et al., 2003; Fernandes et al., 2004; Prawirodirdjo and Bock, 2004; Nocquet et al., 2006; Altamimi et al., 2012; Saria et al., 2013, 2014). Different publications have then used combination of geodetic observations with earthquake slip vectors, or combinations of geodetic data, transform faults orientation and magnetic anomalies in the Indian Ocean and Red Sea, and geological observation along the EARS to investigate the relative motion of the two plates and the geometry of the plate boundary (Hartnady, 1990; Calais et al., 2006; Horner-Johnson et al., 2007; Stamps et al., 2008; Saria et al., 2013). In particular they noticed that the continental part of the plate boundary is significantly complex and formed by multiple rigid blocks moving independently (Figure 1). 

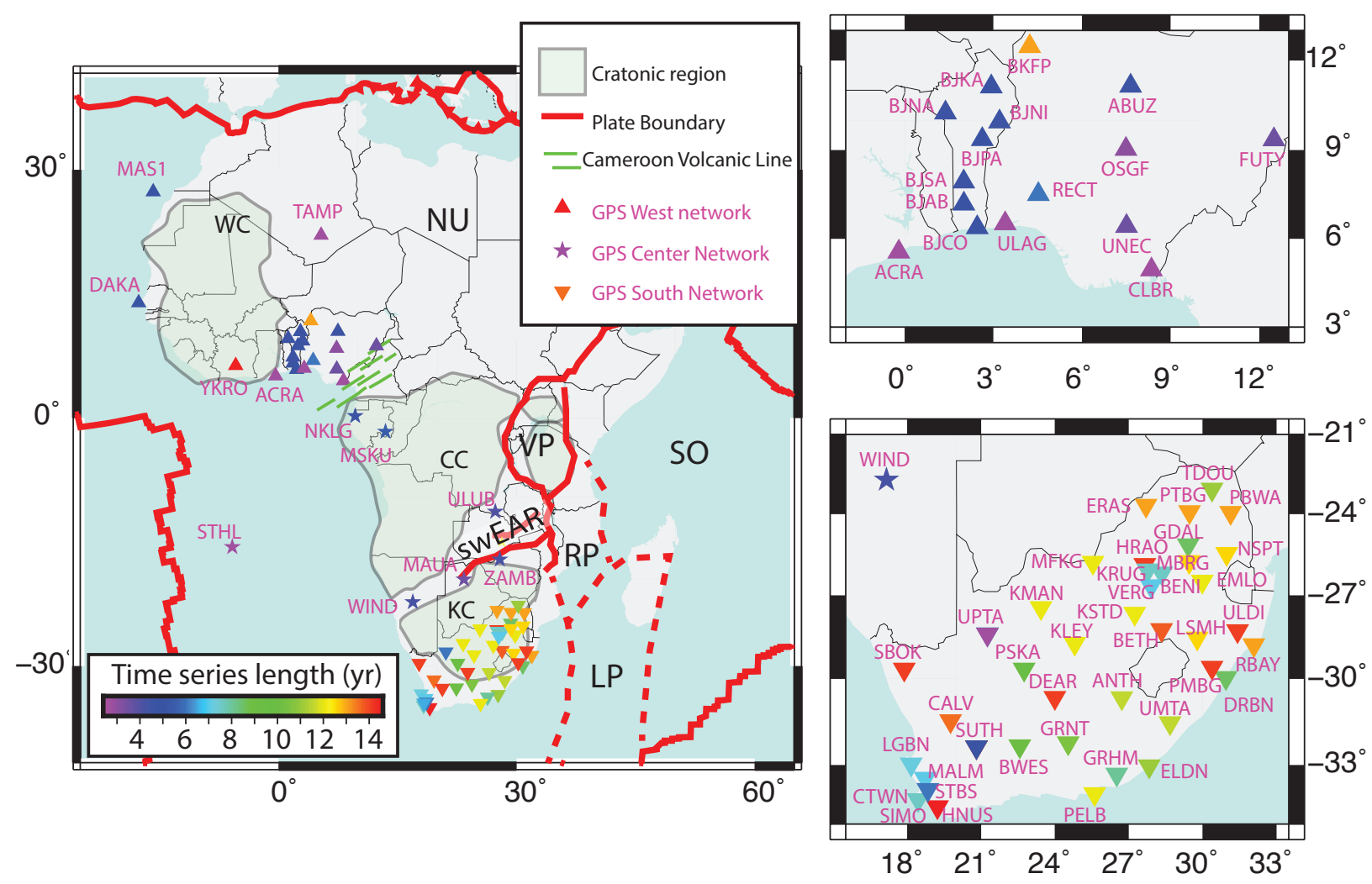

Figure 1: A map of Africa showing the Nubia (NU) and Somalia (SO) plates and the three microplates: Victoria Plate (VP), Rovuma Plate (RP), and Lwandle Plate (LP). The swEAR indicates the South West continuation of the EAR. Green lines indicate the Cameroon volcanic line, WC indicates the West African craton, CC the Congo craton, and KC the Kalahari Craton (from Begg et al. (2009)). Boundaries between plates are represented by red solid and dashed lines, indicating well-defined and assumed boundaries respectively (From Bird (2003) and Stamps et al. (2008)). On the Nubia plate, the three cratons (West African, Congo, and Kalahari) are labeled. GPS sites are color coded by time series length with a symbol indicating the regional network to which they belong. The right side shows enlarged maps of the Western (top) and Southern (bottom) networks. 


\section{CHAPTER TWO:}

\section{DATA ACQUISITION AND PROCESSING}

All of the publically available continuous GPS (cGPS) data within stable Nubia was used for this study. The data was downloaded from different projects stored in the following archives: TRIGNET (ftp://ftp.trignet.co.za), AFREF (ftp://ftp.afrefdata.org), NIGNET (http://server.nignet.net/data), UNAVCO (ftp://data-out.unavco.org/), and CDDIS (http://cddis.nasa.gov/). In order to obtain a reliable velocity field, only sites with at least 2.5 years of observations was used (Blewitt,and Lavallée, 2002; Bennett et al., 2007; Malservisi et al., 2013).

The sites were categorized into three main regions: South, corresponding to the Kalahari craton and South Africa (46 sites, mainly TrigNet sites, reverse triangle in figure 1); Central, corresponding to the sites in the Congo Basin and in the area between the southeastern branch of the EARS and the Cameroon Belt (7 sites, stars in figure 1); and West, including the sites in the West African Craton, and those northwest of the Cameroon belt (mainly NigNet and AMMA sites, 21 sites, triangle in figure 1) (Table 1). Although the amount of data analyzed is still far from ideal for a large plate like Nubia, the velocity field presented here shows a significant improvement in time series length and plate coverage with respect to Malservisi et al., (2013) and Saria et al., (2013). Daily static positions were obtained for each site with at least 20 hours of dual frequency observations. Data were processed using the GIPSY-OASIS 6.2 software (Lichten and 
Border, 1987) and the Precise Point Positioning (PPP) method described by Zumberge et al., (1997) using orbits and clock provided by JPL. Phase ambiguity resolution was performed using the single receiver algorithm (Bertiger et al., 2010). FES2004 oceanloading correction model ((Lyard et al., 2006), http://holt.oso.chalmers.se/loading/) was also applied. Vienna Mapping Functions (VMF1) (Boehm et al., 2006) were used to calculate the tropospheric delay. The daily solutions were then aligned with IGb08 (Rebischung et al., 2011) through daily seven-parameter transformations (x-files) provided by JPL. The atmospheric pressure loading was not corrected because the study focus on horizontal deformation, while the atmospheric pressure loading mainly affects the vertical component (van Dam et al., 1994; Tregoning et al., 2005). Although daily GPS solutions have three components (North, East, and Up), the study focus on the horizontal ones to compute the Euler vectors (McKenzie and Parker, 1967; Morgan, 1968) used to study the rigid motion of the Nubia plate.

The obtained time series were analyzed for long-term trend to compute the secular velocities of each site. Each component (North-South, East-West, and Up-Down) was analyzed independently (Figure 2). Daily solutions with nominal uncertainties larger than 5 times the average uncertainty are normally associated with problematic observations (e.g. large gaps in the observation file) and were removed from the analysis. Time series were corrected for jumps due to known equipment replacement or co-seismic signals. Each time series was further inspected visually and with the help of the MATLAB code PATV (Selesnick et al., 2012) to identify other unknown jumps. Each component of the time series was then fit using the equation

$$
x\left(t_{i}\right)=a+v t_{i}+b \cos \left(2 \pi t_{i}+\phi_{a}\right)+c \cos \left(4 \pi t_{i}+\phi_{s}\right)+\sum_{j=1}^{m} d_{j} H\left(t_{i}-t_{j}\right)
$$


where $\mathrm{a}$ is the position at reference time, $\mathrm{v}$ is the long-term secular velocity, $\mathrm{b}$ and $\phi_{a}$ are the amplitude and phase of the annual signal, $\mathrm{c}$ and $\phi_{s}$ are the amplitude and phase of the semiannual signal, $m$ is the number of jumps within the time series at time $t_{j}, d_{j}$ is the unknown amplitude of the jump, and $\mathrm{H}\left(\mathrm{t}_{\mathrm{i}}-\mathrm{t}_{\mathrm{j}}\right)$ is the Heaviside function.

Following Malservisi et al., (2015), daily positions that differ by more than 5 times the nominal uncertainties from the computed trend were considered outliers and were removed from the calculation. Then, the time series were fit again without the removed data, in an iterative way, until no outliers were present (generally, a single iteration was enough). The resulting clean time series were then detrended to compute the uncertainties. Note that the application of this method to time series with large and often almost periodic gaps (e.g., TAMP) is problematic. Including the analysis of annual or semiannual signals in such time series affects the long-term rate much more than any estimation of the velocity uncertainties. Therefore, such sites were not used.

The observed changes in GPS position are caused by both antenna motion and noise. When studying plate rigidity, where the residuals can be of the same amplitude as the noise, it is critical to correctly estimate the velocity uncertainties. In the study, velocity uncertainties were estimated using the Allan Variance of the rate (AVR) (Hackl et al., 2011, 2013). The AVR technique has the advantage of being fast, while offering the possibility to use different error models and not being too sensitive to gaps in the 

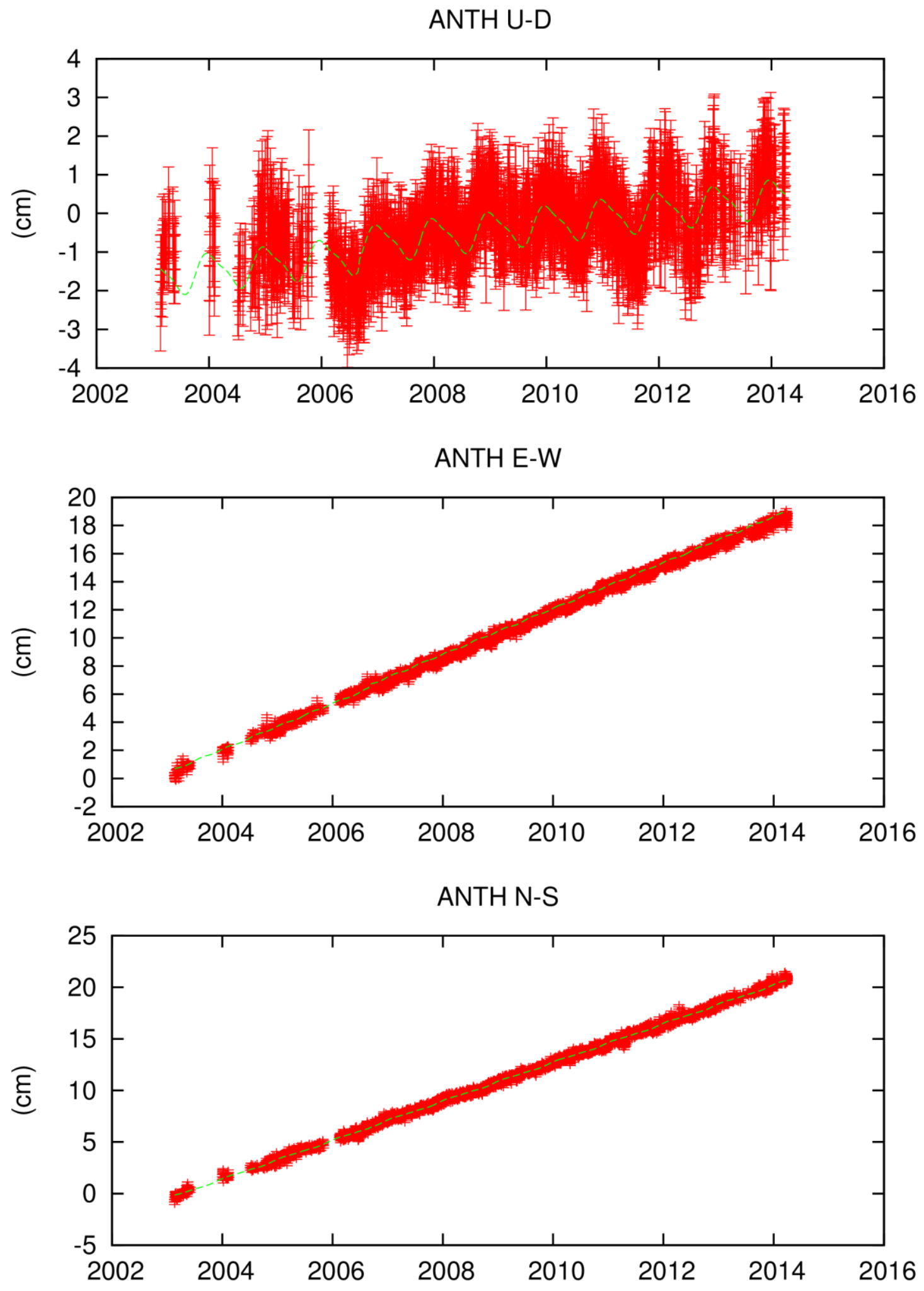

Figure 2: The vertical (Vert) and horizontal (E-W and N-S) time series of ANTH station. 
time series. Thus, it is an ideal technique for this study, where many sites contain gaps up to 1 year in length.

On the other hand, AVR has the disadvantage that the variance can be computed directly only for $1 / 4$ of the total length of the time series, and needs to be extrapolated to the correct length using a prescribed error model. Thus, the results are not significant for time series shorter than 2 years.

Following Malservisi et al., (2013), the uncertainties are computed using a combination of white and power law noise. Although time series were detrended by removing annual and semi-annual signals, the AVR analysis indicates the presence of a periodic signal with a period between 70 and 100 days. Although a full spectral analysis was not conducted to identify such a period, and was not removed in the fit by adding a term to equation 1, a period of 89 days gave the best fit of the Allan Variance of the Rate for almost all the time series; thus that value was used for the calculation of uncertainties. The $1 / 4$ year periodicity ( 89 days) is suggested to be higher harmonic signal which remains after the annual and semi-annual signal has been removed in the time series.

Table 1 has detailed information concerning the geographical position of the stations, their observed velocities, and their associated uncertainties computed by the AVR technique.

The first, second and third group of sites are West, Central and South regions respectively. The site velocities and associated uncertainties are with respect to IGb08. 
Table 1: GPS Data Used for Computation of Euler Vectors for Nubia Cratons.

Site Lat Lon Start End \# of days Lat V Unc Lon V Unc

West

$\begin{array}{llllllllll}\text { ABUZ } & 11.1517 & 7.6487 & 2011.0007 & 2014.4915 & 1181 & 19.12 & 0.19 & 22.29 & 0.85\end{array}$ $\begin{array}{llllllllll}\text { acra } & 5.5581 & -0.2030 & 2011.0664 & 2013.9987 & 761 & 16.96 & 0.23 & 21.91 & 0.60\end{array}$ $\begin{array}{llllllllll}\text { BJAB } & 7.1823 & 2.0005 & 2009.6674 & 2014.4941 & 1349 & 19.49 & 0.18 & 22.58 & 0.56\end{array}$ $\begin{array}{llllllllll}\text { BJCO } & 6.3847 & 2.4500 & 2009.6674 & 2014.4833 & 1409 & 18.53 & 0.12 & 21.72 & 0.49\end{array}$ $\begin{array}{llllllllll}\text { bjka } & 11.1247 & 2.9280 & 2009.6674 & 2014.4941 & 1229 & 17.93 & 0.08 & 22.34 & 0.49\end{array}$ $\begin{array}{llllllllll}\text { bjna } & 10.2532 & 1.3807 & 2009.9138 & 2014.4915 & 1046 & 19.69 & 0.35 & 20.95 & 0.52\end{array}$ $\begin{array}{llllllllll}\text { bjni } & 9.9513 & 3.2040 & 2009.6674 & 2014.2177 & 642 & 19.59 & 0.17 & 21.01 & 0.52\end{array}$ $\begin{array}{llllllllll}\text { BJPA } & 9.3575 & 2.6257 & 2009.6674 & 2014.4941 & 1361 & 18.84 & 0.15 & 22.41 & 0.22\end{array}$ $\begin{array}{llllllllll}\text { BJSA } & 7.9278 & 1.9932 & 2009.6674 & 2014.2642 & 753 & 19.08 & 0.22 & 22.03 & 0.28\end{array}$ $\begin{array}{llllllllll}\text { bkfp } & 12.4686 & 4.2292 & 2011.0007 & 2014.4941 & 1197 & 18.10 & 0.26 & 20.64 & 0.47\end{array}$ $\begin{array}{llllllllll}\text { CLBR } & 4.9503 & 8.3516 & 2011.2142 & 2014.4941 & 554 & 19.39 & 0.33 & 22.13 & 0.51\end{array}$

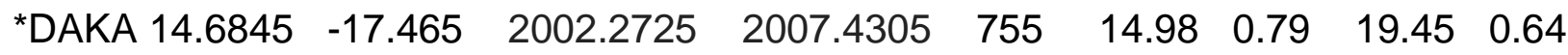

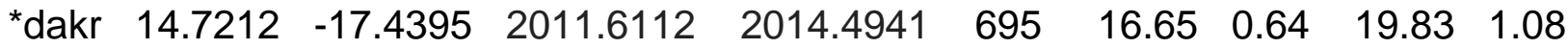
$\begin{array}{llllllllll}\text { FUTY } & 9.3497 & 12.4978 & 2011.0007 & 2014.4941 & 939 & 17.92 & 0.43 & 22.57 & 0.62\end{array}$ $\begin{array}{lllllllll}\text { MAS1 } & 27.7637-15.6333 & 2009.6674 & 2014.4941 & 172 & 16.91 & 0.30 & 16.32 & 0.28\end{array}$ $\begin{array}{llllllllll}\text { OSGF } & 9.0277 & 7.4863 & 2011.1814 & 2014.2916 & 1010 & 18.63 & 0.15 & 21.78 & 0.28\end{array}$ $\begin{array}{llllllllll}\text { RECT } & 7.5055 & 4.5245 & 2007.5510 & 2013.3087 & 548 & 19.27 & 0.13 & 22.45 & 0.17\end{array}$ $\begin{array}{llllllllll}\text { ulag } & 6.5173 & 3.3976 & 2011.0007 & 2013.7988 & 896 & 18.35 & 0.17 & 23.65 & 0.56\end{array}$

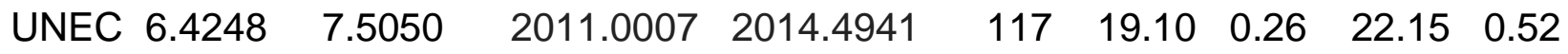
$\begin{array}{llllllllll}\text { ykro } & 6.8706 & -5.2401 & 1999.6140 & 2014.4941 & 1174 & 18.15 & 0.08 & 22.60 & 0.09\end{array}$ 
Table 1 (Continued)

Site Lat Lon Start End \# of days Lat V Unc Lon V Unc

Central

$\begin{array}{lllllllll}\text { MAUA -19.9022 } & 23.5284 & 2011.0007 & 2014.4860 & 1192 & 19.11 & 0.35 & 19.53 & 0.21\end{array}$

$\begin{array}{llllllllll}\text { msku } & -1.6316 & 13.5520 & 2001.3936 & 2007.2471 & 921 & 19.66 & 0.33 & 17.44 & 0.37\end{array}$

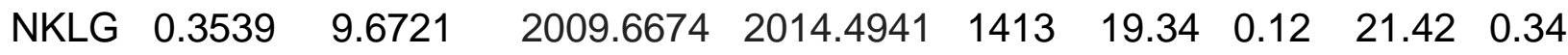

$\begin{array}{lllllllll}\text { STHL -15.9425 } & -5.6673 & 2011.6495 & 2014.4941 & 938 & 18.16 & 0.20 & 22.22 & 0.27\end{array}$

$\begin{array}{llllllllll}\text { ulub } & -11.6306 & 27.4849 & 2009.9000 & 2014.0452 & 1035 & 19.00 & 0.27 & 23.19 & 0.19\end{array}$

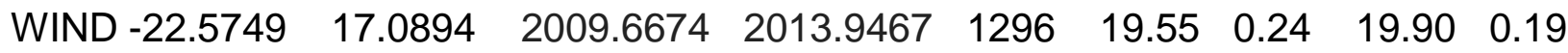

$\begin{array}{llllllllll}\text { ZAMB } & -15.4255 & 28.3110 & 2002.4175 & 2014.4941 & 2418 & 18.49 & 0.06 & 19.35 & 0.08\end{array}$

South

$\begin{array}{llllllllll}\text { ANTH } & -30.6798 & 26.7160 & 2003.0363 & 2014.4941 & 3319 & 18.50 & 0.11 & 15.59 & 0.14\end{array}$ $\begin{array}{llllllllll}\text { beni } & -26.1953 & 28.3413 & 2007.0527 & 2014.4941 & 2097 & 19.14 & 0.09 & 16.99 & 0.14\end{array}$ $\begin{array}{llllllllll}\text { beth } & -28.2498 & 28.3342 & 2000.5613 & 2014.4941 & 4160 & 19.34 & 0.11 & 15.93 & 0.12\end{array}$ $\begin{array}{llllllllll}\text { bwes } & -32.3474 & 22.5736 & 2003.7837 & 2014.4941 & 2883 & 19.41 & 0.10 & 15.95 & 0.24\end{array}$

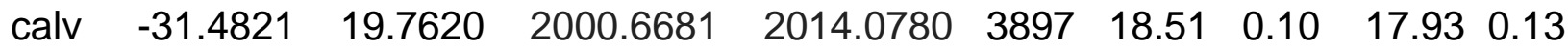

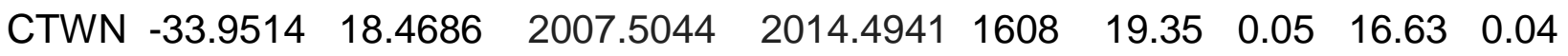
$\begin{array}{llllllllll}\text { DEAR } & -30.6652 & 23.9926 & 2000.6681 & 2014.4941 & 3946 & 18.71 & 0.12 & 16.95 & 0.16\end{array}$ $\begin{array}{llllllllll}\text { drbn } & -29.9650 & 30.9467 & 2000.5831 & 2010.3245 & 1814 & 17.20 & 0.08 & 16.26 & 0.16\end{array}$ $\begin{array}{llllllllll}\text { ELDN } & -33.0385 & 27.8288 & 2000.5831 & 2013.5195 & 3106 & 18.73 & 0.12 & 15.92 & 0.11\end{array}$

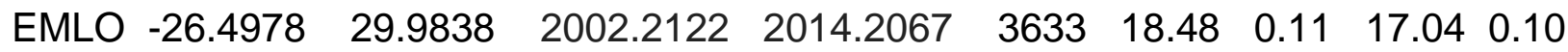
$\begin{array}{llllllllll}\text { ERAS } & -23.6867 & 27.6961 & 2001.1581 & 2014.0780 & 3519 & 18.56 & 0.07 & 18.15 & 0.14\end{array}$

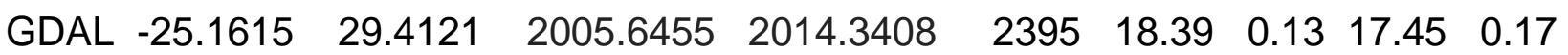


Table 1 (Continued)

Site Lat Lon Start End \# of days Lat V Unc Lon V Unc

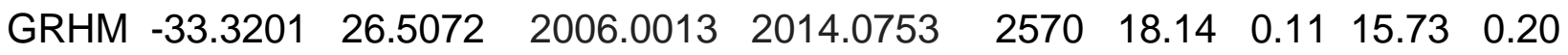

$\begin{array}{llllllllll}\text { grnt } & -32.2480 & 24.5345 & 2003.4962 & 2014.0753 & 3166 & 19.63 & 0.16 & 18.02 & 0.22\end{array}$

$\begin{array}{llllllllll}* \text { *harb } & -25.8870 & 27.7072 & 2009.6674 & 2014.4941 & 1599 & 19.01 & 0.30 & 17.43 & 0.35\end{array}$

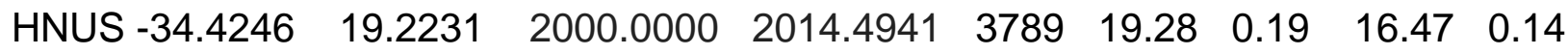

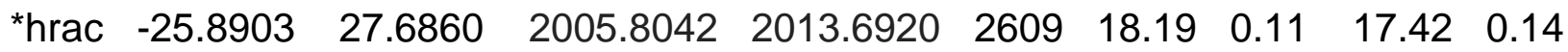

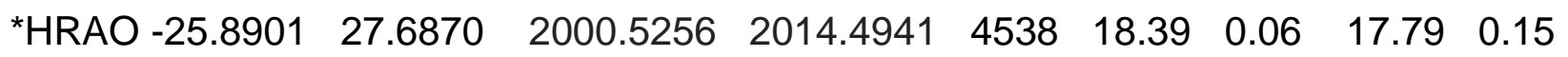

$\begin{array}{llllllllll}\text { KLEY } & -28.7430 & 24.8065 & 2000.5476 & 2014.0753 & 3524 & 18.48 & 0.12 & 16.60 & 0.11\end{array}$

$\begin{array}{llllllllll}\text { kman } & -27.4608 & 23.4325 & 2002.2916 & 2014.0753 & 3687 & 18.29 & 0.07 & 18.23 & 0.13\end{array}$

$\begin{array}{llllllllll}\text { krug } & -26.0829 & 27.7663 & 2007.0582 & 2014.3326 & 2194 & 17.75 & 0.13 & 15.29 & 0.17\end{array}$

$\begin{array}{llllllllll}\text { kstd } & -27.6636 & 27.2401 & 2002.2970 & 2014.0753 & 3189 & 18.33 & 0.11 & 17.66 & 0.17\end{array}$

$\begin{array}{llllllllll}\text { LGBN } & -32.9725 & 18.1578 & 2006.7406 & 2014.1875 & 2500 & 19.55 & 0.17 & 17.19 & 0.15\end{array}$

$\begin{array}{llllllllll}\text { LSMH } & -28.5577 & 29.7815 & 2000.5750 & 2014.0753 & 3608 & 17.81 & 0.09 & 16.62 & 0.12\end{array}$

$\begin{array}{lllllllll}\text { MALM -33.4638 } & 18.7308 & 2006.8966 & 2014.0753 & 2365 & 18.75 & 0.20 & 16.54 & 0.29\end{array}$

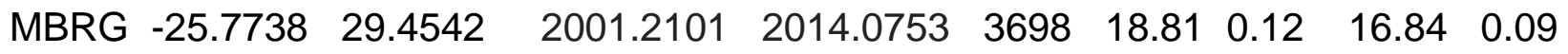

$\begin{array}{llllllllll}\text { mfkg } & -25.8050 & 25.5400 & 2002.3245 & 2014.4941 & 3341 & 20.41 & 0.09 & 17.62 & 0.08\end{array}$

$\begin{array}{llllllllll}\text { NSPT } & -25.4753 & 30.9752 & 2001.2101 & 2014.0753 & 3551 & 17.64 & 0.08 & 17.31 & 0.13\end{array}$

$\begin{array}{llllllllll}\text { pbwa } & -23.9515 & 31.1343 & 2001.4401 & 2014.4941 & 3741 & 17.47 & 0.10 & 17.63 & 0.08\end{array}$

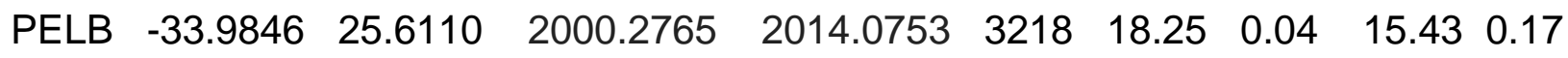

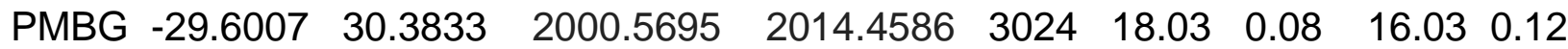

$\begin{array}{llllllllll}\text { PSKA } & -29.6676 & 22.7493 & 2004.5859 & 2014.0753 & 3124 & 18.99 & 0.14 & 17.34 & 0.18\end{array}$

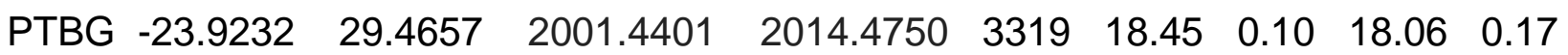


Table 1 (Continued)

Site Lat Lon Start End \# of days Lat V Unc Lon V Unc $\begin{array}{llllllllll}\text { RBAY } & -28.7955 & 32.0784 & 2000.7556 & 2014.4941 & 2203 & 17.62 & 0.17 & 16.25 & 0.28\end{array}$

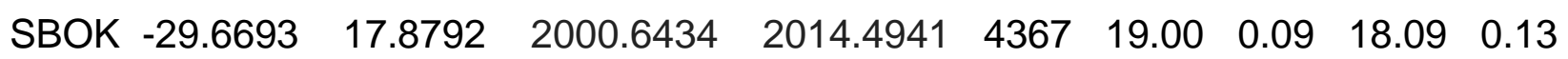

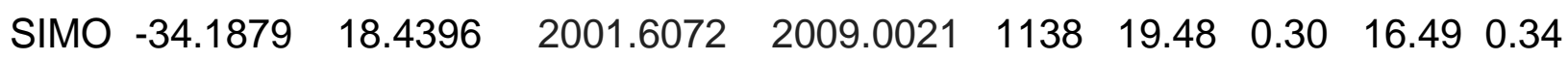

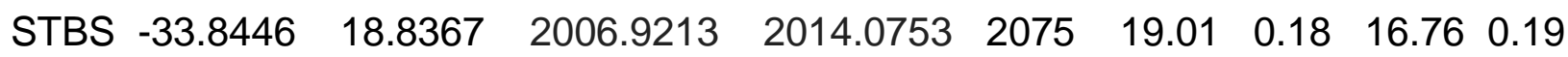
$\begin{array}{llllllllll}\text { *sut1 } & -32.3802 & 20.8105 & 2010.0013 & 2014.0753 & 1374 & 19.31 & 0.45 & 16.08 & 0.37\end{array}$

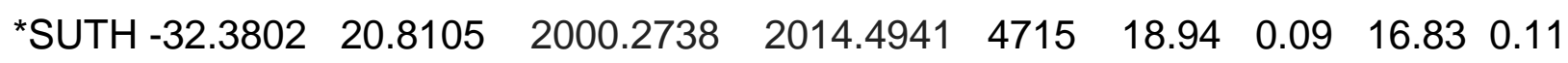

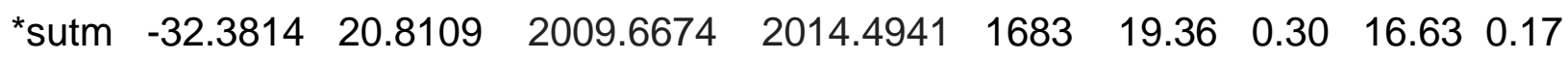
$\begin{array}{llllllllll}\text { tdou } & -23.0799 & 30.3840 & 2003.4579 & 2014.4941 & 3114 & 15.91 & 0.14 & 19.43 & 0.14\end{array}$ $\begin{array}{llllllllll}\text { ULDI } & -28.2931 & 31.4209 & 2000.7146 & 2014.4941 & 4013 & 18.08 & 0.02 & 16.01 & 0.05\end{array}$ $\begin{array}{llllllllll}\text { umta } & -31.5488 & 28.6725 & 2000.5613 & 2011.9233 & 3192 & 17.16 & 0.13 & 16.20 & 0.18\end{array}$ $\begin{array}{lllllllll}* \text { *UPTA -28.4072 } & 21.2576 & 2007.8330 & 2014.0753 & 2165 & 19.65 & 0.20 & 17.87 & 0.23\end{array}$

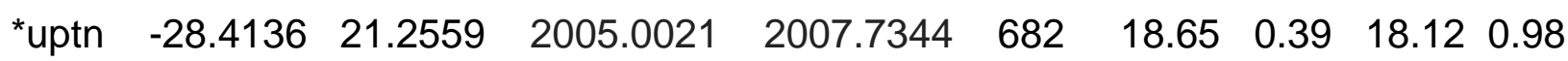

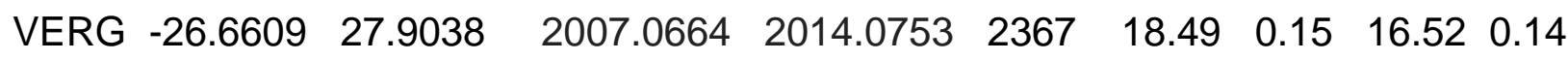
The first, second and third group of sites are West, Central and South regions respectively. The site velocities and associated uncertainties are with respect to IGb08. Stations in small letters were not used in calculation of the Euler vectors of the three regions. Stations with $\left({ }^{*}\right)$ are co-located sites. 


\section{CHAPTER THREE: \\ RIGID BLOCK MOTION}

To compute the angular velocities of the West, Central, South, West-Central, SouthCentral and Nubia regions, the plate rigidity assumption (vertical velocity is zero and plate move horizontally) was used, thus only stations far $(>100 \mathrm{~km})$ from major known plate boundaries were considered. This eliminates sites in known active regions like Atlas Mountain, Cape Verde, or along the EARS. Similarly, all of the stations identified as problematic by Malservisi et al., (2013) and Hackl et al., (2011) were eliminated. A lower weight in the Euler vector fit and residual interpretation were assigned to all the stations which the combined white and power law noise error model does not fit the AVR. Often these sites correspond to time series affected by very large gaps or problematic behavior (e.g., BFTN in South Africa that present some highly non linear behavior for few months between 2008 and 2011) (Figure 3). Stations with the longest time series were selected for analysis Malservisi et al., (2013) for sites with multiple stations. The Euler theorem was applied to calculate the angular velocity vectors of each region with respect to the IGb08 reference frame.

Apart from calculating Euler vectors for the three main regions, the Euler vectors associated with the combination of West+Central, South+Central, and the full Nubia plate were also calculated. The methodology described by Plattner et al., (2007) helped to identity the stations which produce the best-fitting Euler vector of the region as a 

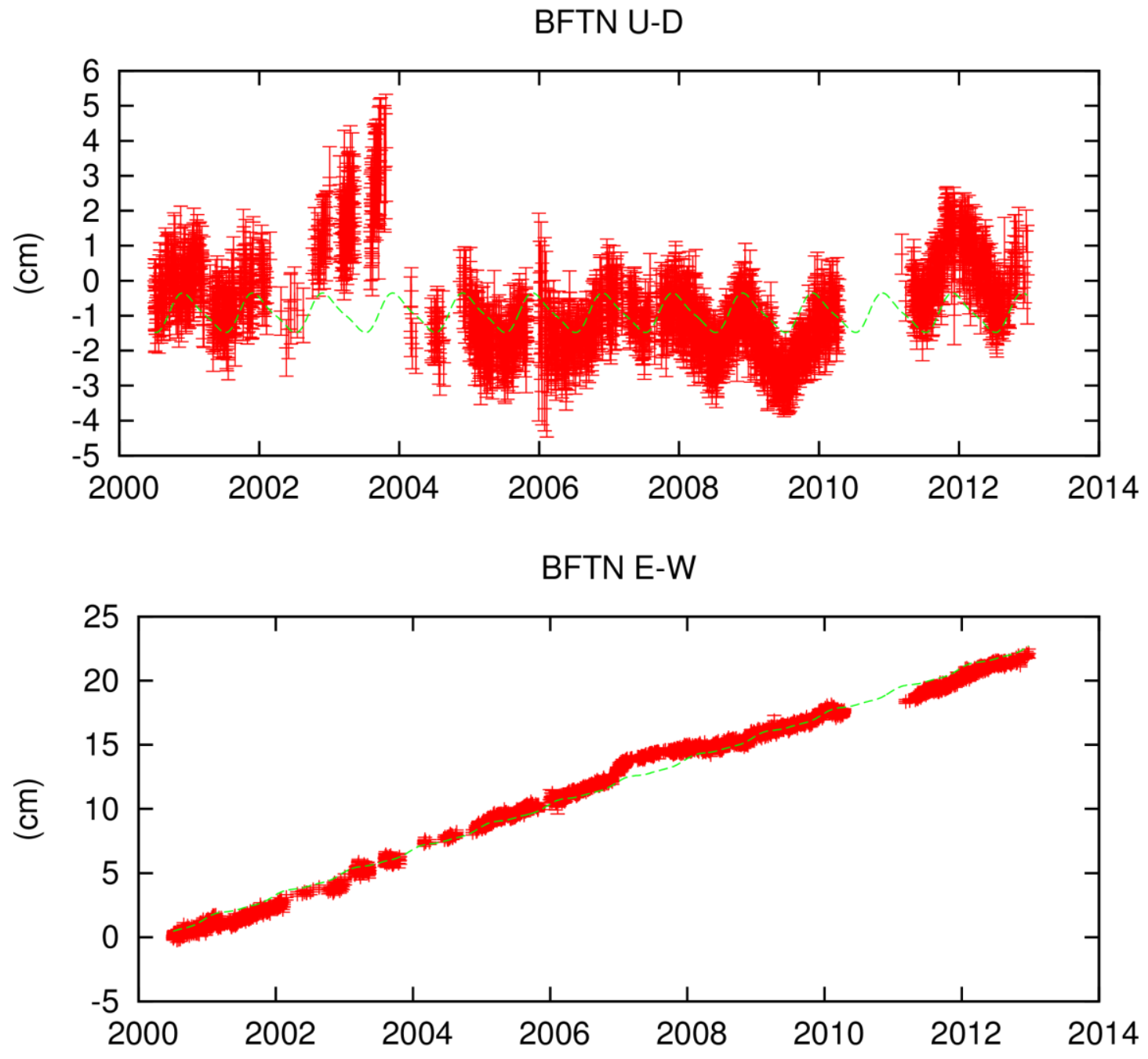

BFTN N-S

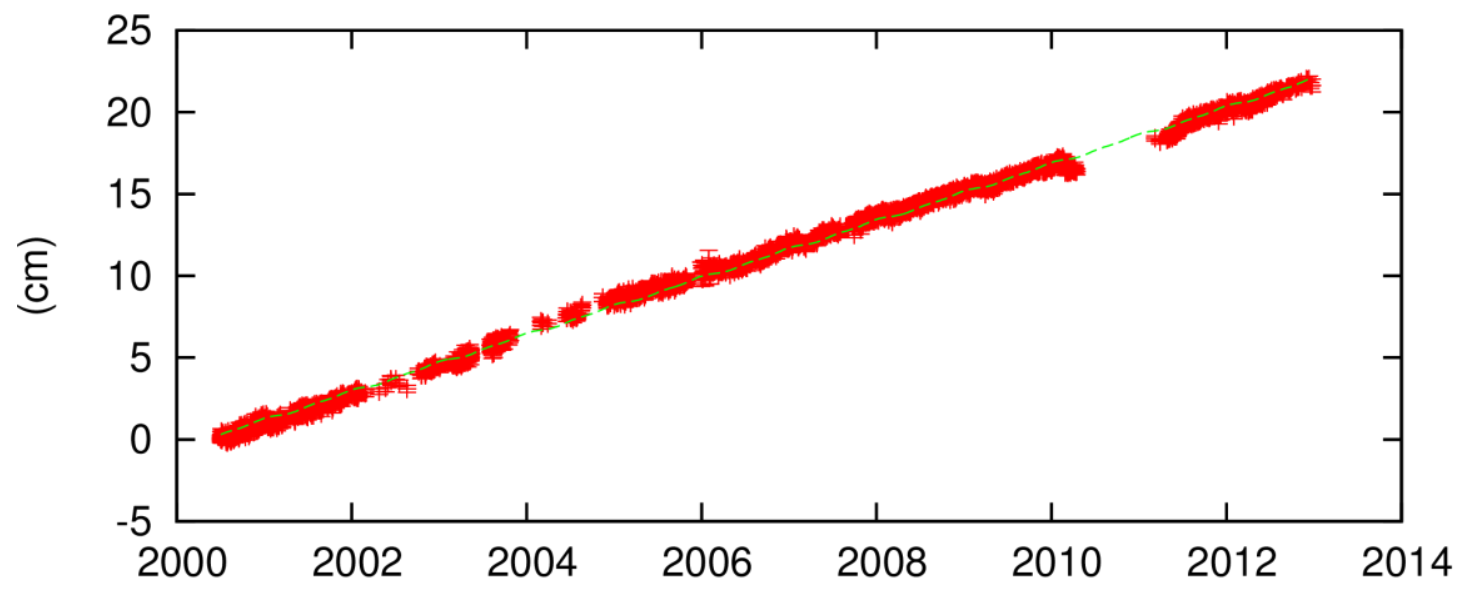

Figure 3: The vertical (Vert) and horizontal (E-W and N-S) time series of BFTN station. 
rigid body with respect to IGb08. In addition, Jackknife method similar to the one described by Malservisi et al., (2013) was applied. Using this approach, 21, 7, and 46 rotation poles for the West, Central and South regions respectively were calculated, leaving out one station from each dataset to compute a new Euler vector. Using the Fratio test (Stein and Gordon 1984) for each iteration was important in defining the significance of a station for determining an Euler vector. This process identifies the subset of stations that were used for the Euler vector calculations. The stations used to compute the Euler vectors of the three regions were then combined to determine the Euler vectors of West+Central, South+Central and Nubia regions. The reduced $\chi^{2}$ of the obtained Euler vectors varied from 2.58 to 7.95 , and the average rate residuals range from 0.33 to 0.61 $\mathrm{mm} / \mathrm{yr}$. The Euler vectors are described in Table 2 and Table 3.

It is important to note that for each region, a subset of stations was identified that gives a reduced $\chi^{2} \sim 1$. These stations generally have relatively long timeseries, but are often sparsely distributed and probably not completely representative of the local rigid block motion. Furthermore, it was noted that the residuals of motion described by the Euler vectors computed with the larger dataset have essentially random orientation (Figure 4, $5,6,7$ and 8 ) suggesting that the large reduced $\chi^{2}$ is probably more related to underestimated uncertainties than to real motion with respect to the rigid plate assumption. It was observed that all the Euler vectors calculated with the subset of stations that give areduced $\chi^{2} \sim 1$ are compatible within uncertainties with the Euler vectors calculated with the larger dataset. For these reasons, the solutions with more stations were prefered even if the reduced $\chi^{2}$ is significantly larger than 1. 


\subsection{West Region Euler Vector}

In the West region there were 21 stations in total. TAMP was eliminated in velocities analysis because it had a very large residual due to large gaps. In the case of the two co-located stations DAKA and DAKR the later was kept. Only 12 out of the remaining 19 stations were considered in determining the Euler vector indicated as WEST in Table 2. Seven stations (ACRA, BJKA, BJNA, BJNI, BKFP, ULAG, and YKRO) were not used (Figure 4). There is no physical explanation for the large residuals of BJKA, BJNA,BJNI,BKFP ULAG. It is likely that the station ACRA is influenced by the anthropogenic activity (both oil and groundwater extraction) or by costal deformation. The high residuals associated with YKRO could be associated with fluctuation of the nearby Lake Kossou (similar effects were suggest for different sites close to lakes in South Africa by Malservisi et al., (2013)). The reduced $\chi^{2}$ of resulting Euler vector fit is 2.58 and the mean rate residual is $0.49 \mathrm{~mm} / \mathrm{yr}$. The moderately large reduced $\chi^{2}$ could be related to underestimated uncertainties although there is need to note that there are some significant residuals that could be also related to local sources of deformation.

\subsection{Central Region Euler Vector}

This is the least sampled region with only 7 stations. Malservisi et al., (2013) and Saria et al., (2013) showed that stations MSKU and ULUB have large residuals and were not used for calculations. Using the remaining 5 stations (Figure 4) resulted in a reduced $\chi^{2}$ of 2.65 and rate residual of $0.33 \mathrm{~mm} / \mathrm{yr}$ (pole CENTRAL in Table 2). 


\subsection{South Region Euler Vector}

South Africa is the region with the densest GPS coverage (66 stations), however stations which were described as problematic by Hackl et al., (2011) and Malservisi et al., (2013) with short time series or large gaps, were eliminated, leaving only 46 stations. This region also had the stations with longest time series and hence low velocity uncertainities which can explain the higher reduced $\chi^{2}$. Of the co-located sites HARB, HRAC, and HRAO; SUTH, SUT1, and SUTM, and UPTA, and UPTN the prefered stations were HRAO, SUTH and UPTA respectively. Out of the remaining 41 stations, 28 stations were used for the Euler vector determination while 13 stations: GRNT, KRUG, MFKG,PBWA,UMTA, TDOU (as already noted by Malservisi et al., 2013 and Saria et al., 2013) and BENI, BETH, BWES,CALV, DRBN, KSTD, KMAN due to large residuals (Figure 4) were not included. The reduced $\chi^{2}$ and average residual are 7.95 and $0.39 \mathrm{~mm} / \mathrm{yr}$ respectively (pole SOUTH in Table 2). The possibility of reducing the reduced $\chi^{2}$ by using the sites in the driest and most stable part of the network identified by Malservisi et al., (2013) was tested, but there was no significant improvement. Note that the homogeneous velocity field in the Cape Town area that Malservisi et al., (2013) suggested to be related to strain accumulation associated with the seismic hazards of the area (Aderemi et al., 2013) is no longer visible, indicating that it is possible it was only an artifact due to the length of the time series. 


\subsection{Combined Euler Vectors}

Apart for the single region Euler vectors, rigid plate motion of combined regions were computed. For this task only the sites utilized to compute the Euler vector for corresponding to each regional network were considered. As a result, poles for the South+Center region, West+Center region, and full Nubia (Figure 8) were obtained.

\subsection{West-Central Region Euler Vector}

To obtain this Euler vector (WEST_C in Table 2) three extra stations were eliminated (FUTY, BJBA and BJPA) with respect to the subset of GPS points used for the WEST and CENTRAL Euler poles since they have residuals that are significantly larger than expected. Using the remaining 14 stations (Figure 8), the resulting fit for the Euler vector has a reduced $\chi^{2}$ and mean rate residual of 4.89 and $0.61 \mathrm{~mm} / \mathrm{yr}$ respectively.

\subsection{South-Central Region Euler Vector}

The region is composed of stations in both South and Central regions (SOUTH_C). Only 33 out of the 48 stations (Figure 8 ) in the two regional networks are used for the computation of SOUTH_C Euler vector (Table 2). The reduced $\chi^{2}$ and mean rate residual for the combined Euler vector calculations are respectively 7.27 and $0.41 \mathrm{~mm} / \mathrm{yr}$. 


\subsection{Nubia Euler Vector}

To calculate the NUBIA pole, only the 42 sites used to calculate the WEST_C and SOUTH_C poles (Figure 8 ) were utilized. The reduced $\chi^{2}$ and mean rate residual in this Euler vector calculation are 6.79 and $0.47 \mathrm{~mm} / \mathrm{yr}$ respectively (Table 2).

Although the noise level was evaluated using AVR and included colored noise, it is possible that the error model used in the AVR interpolation (periodic signals, power-law and white noise) underestimates the uncertainties. For example, during interpolation, the periodic signal could mask a part of the highly time-correlated noise (random walk), leading to a faster decrease of uncertainties for longer time series. Another possibility is that the importance of flicker noise is much higher than the importance of higher time correlated noise hence this later would be visible only with time series significantly longer. In both cases, the error model predicts smaller uncertainties resulting in the large reduced $\chi^{2}$.

Note that while the average residual rate from all of the Euler vectors calculations varies from 0.3 to $0.4 \mathrm{~mm} / \mathrm{yr}$, the mean residual rate for the WEST_C is $0.6 \mathrm{~mm} / \mathrm{yr}$. In all the Euler vectors calculations, the majority of the stations presents residuals smaller than 0.5 $\mathrm{mm} / \mathrm{yr}$ indicating a possible upper limit for the internal deformation of the Nubia plate. The few stations with residuals of $1 \mathrm{~mm} / \mathrm{yr}$ or larger appear to be stations with problematic behavior such as BFTN (e.g. figure 3) has a non-linear trend, short time series, or gaps. All other stations with residuals between 0.5 and $1.0 \mathrm{~mm} / \mathrm{yr}$ are more likely be affected by local phenomena (subsidence or anthropogenic effects) rather than tectonic motion. 
Table 2: Region Euler Vectors with Respect to IGb08 in Geographic Coordinates Euler V. Stat.\# Red. $\chi^{2}$ Res. $(\mathrm{mm} / \mathrm{yr})$ Lat $\left({ }^{\circ} \mathrm{N}\right)$ Lon $\left({ }^{\circ} \mathrm{E}\right) \quad \omega\left({ }^{\circ} / \mathrm{My}\right) \quad \sigma \operatorname{Max} \sigma \operatorname{Min}$ Azi. $\begin{array}{llllllllll}\text { CENTRAL } & 5 & 2.65 & 0.33 & 48.29 & -77.15 & 0.2597 \pm 0.0016 & 1.26 & 0.27 & -86.0\end{array}$

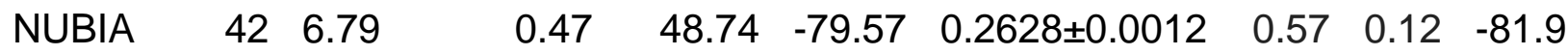
$\begin{array}{llllllllll}\text { SOUTH } & 28 & 7.95 & 0.39 & 48.77 & -80.10 & 0.2638 \pm 0.0025 & 1.17 & 0.14 & -81.2\end{array}$ $\begin{array}{lllllllll}\text { SOUTH_C } 33 & 7.27 & 0.41 & 48.65 & -79.25 & 0.2621 \pm 0.0017 & 0.86 & 0.13 & -81.4\end{array}$

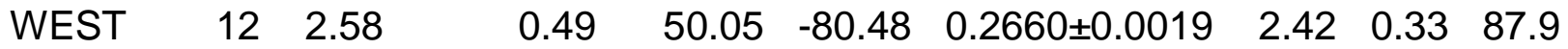

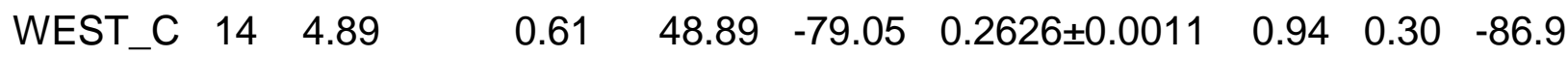

Table 3: Region Cartesian Components and Covariance Matrix of Euler Vectors

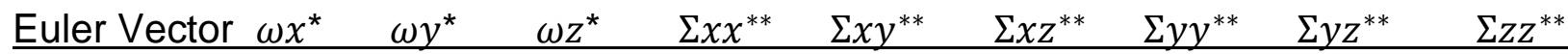

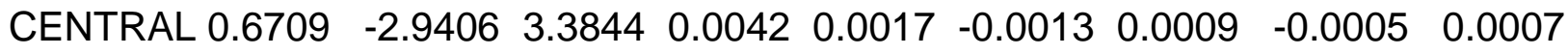

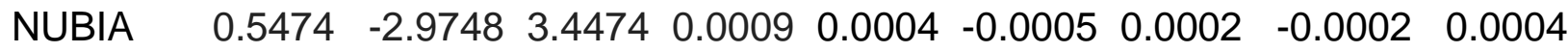

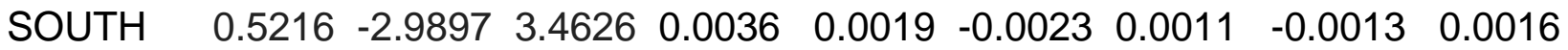
SOUTH_C $0.5635-2.9685 \quad 3.43350 .00190 .0010 \quad-0.00120 .0005 \quad-0.0006 \quad 0.0008$

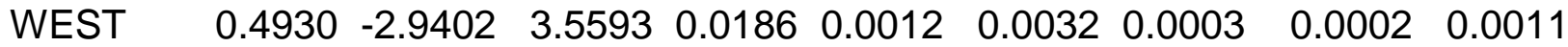

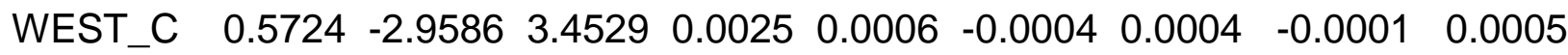
${ }^{*} 10^{-3}(\mathrm{rad} / \mathrm{Myr}) \quad{ }^{* *} 10^{-6}(\mathrm{rad} / \mathrm{My})^{2}$ 

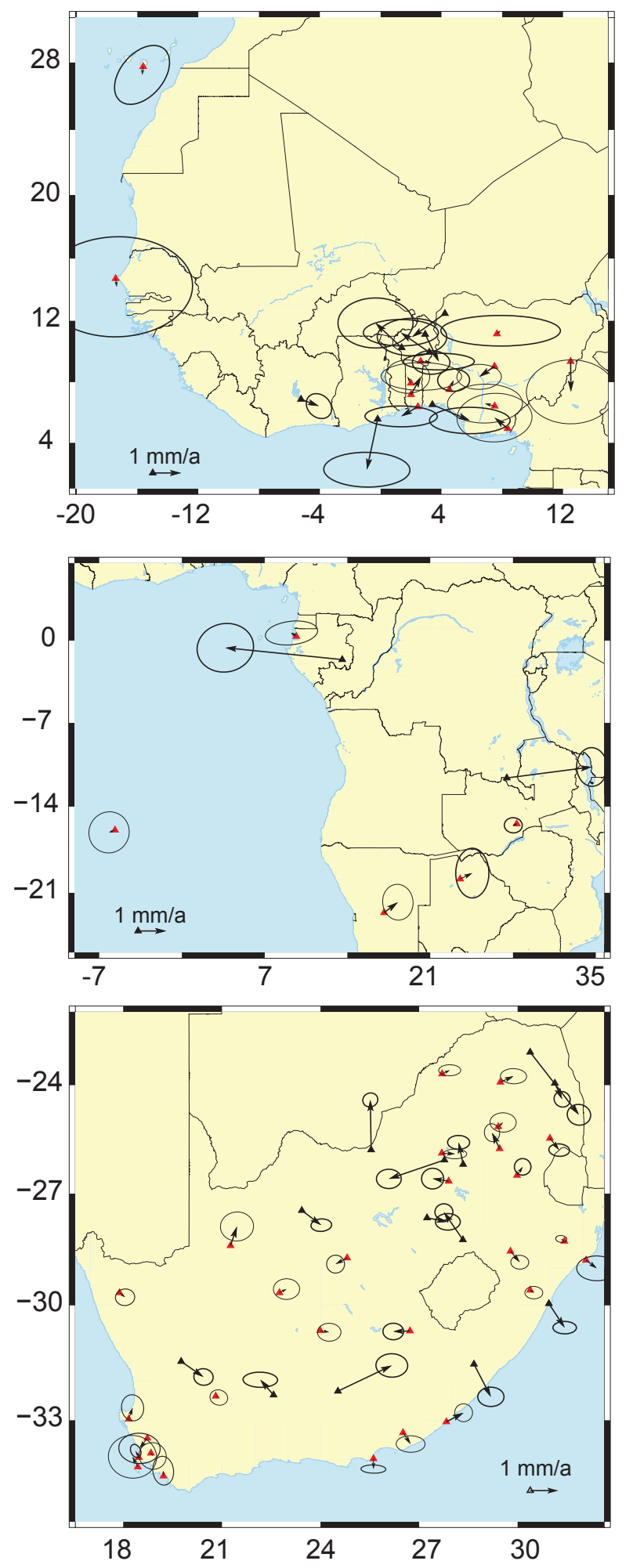

Figure 4: Residuals with respect to the motion described by the Euler vector that minimize the velocity of the red triangles for the three main regions (top to bottom: West, Central, and South). The arrows reppresent the relative motion within each region with respect to the local reference frame thus give an idea of the rigidity of the area. The triangles represent GPS stations; red triangles indicated stations that were used in computation of Euler vector. 

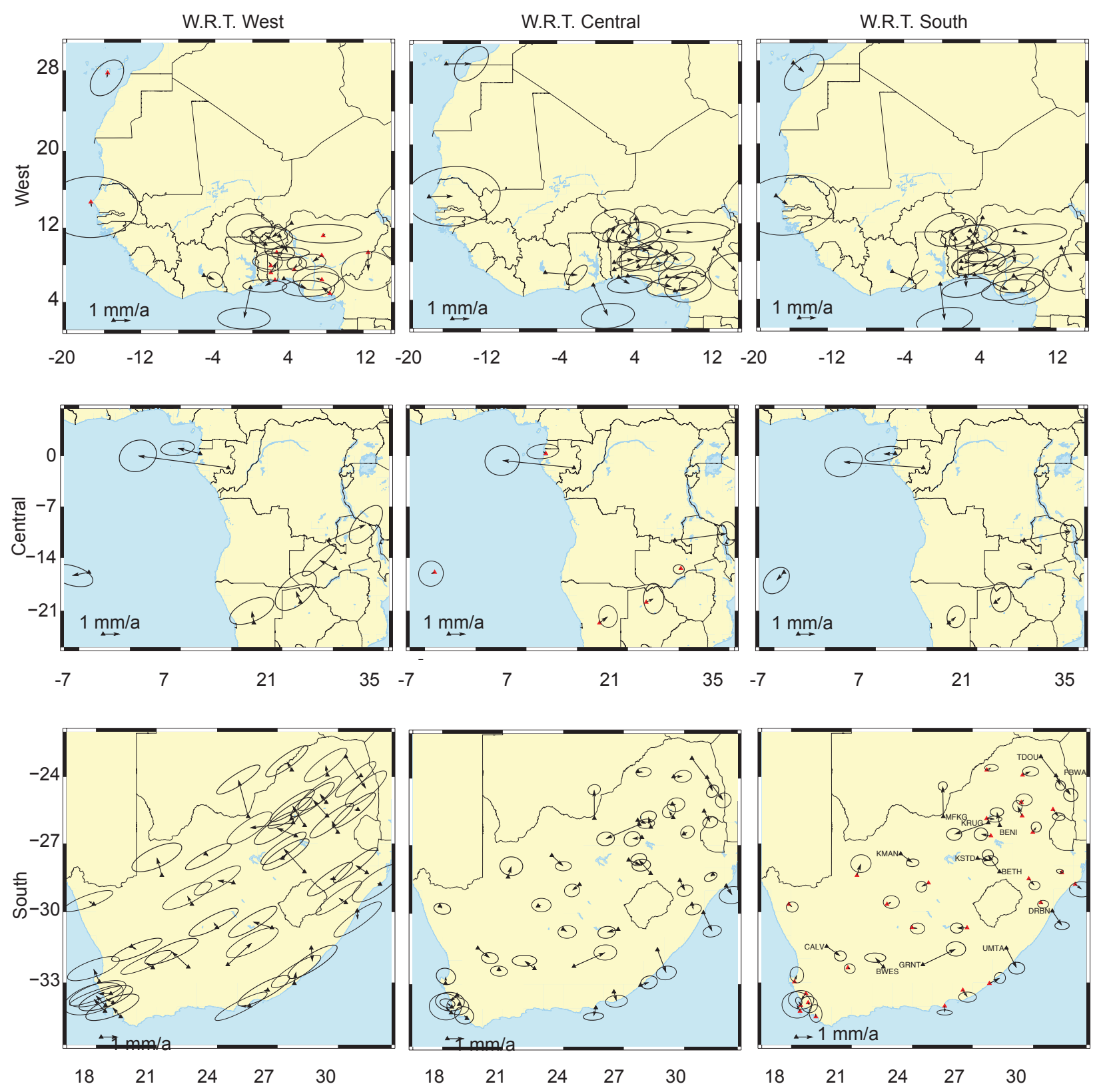

Figure 5:The velocity field of West (W), Central (C), and South (S) regions (from top to bottom), with respect to Euler vectors calculate for Figure 4 (from left to right: West, Central and South Euler poles,). Triangles indicate GPS station. Red triangle represent the GPS stations used in determination of Euler pole. Error ellipse correspond to $95 \%$ confidence. The residual scale is 1 $\mathrm{mm} / \mathrm{yr}$ as indicated in some map (right hand bottom part of the map), this applies to all maps. 

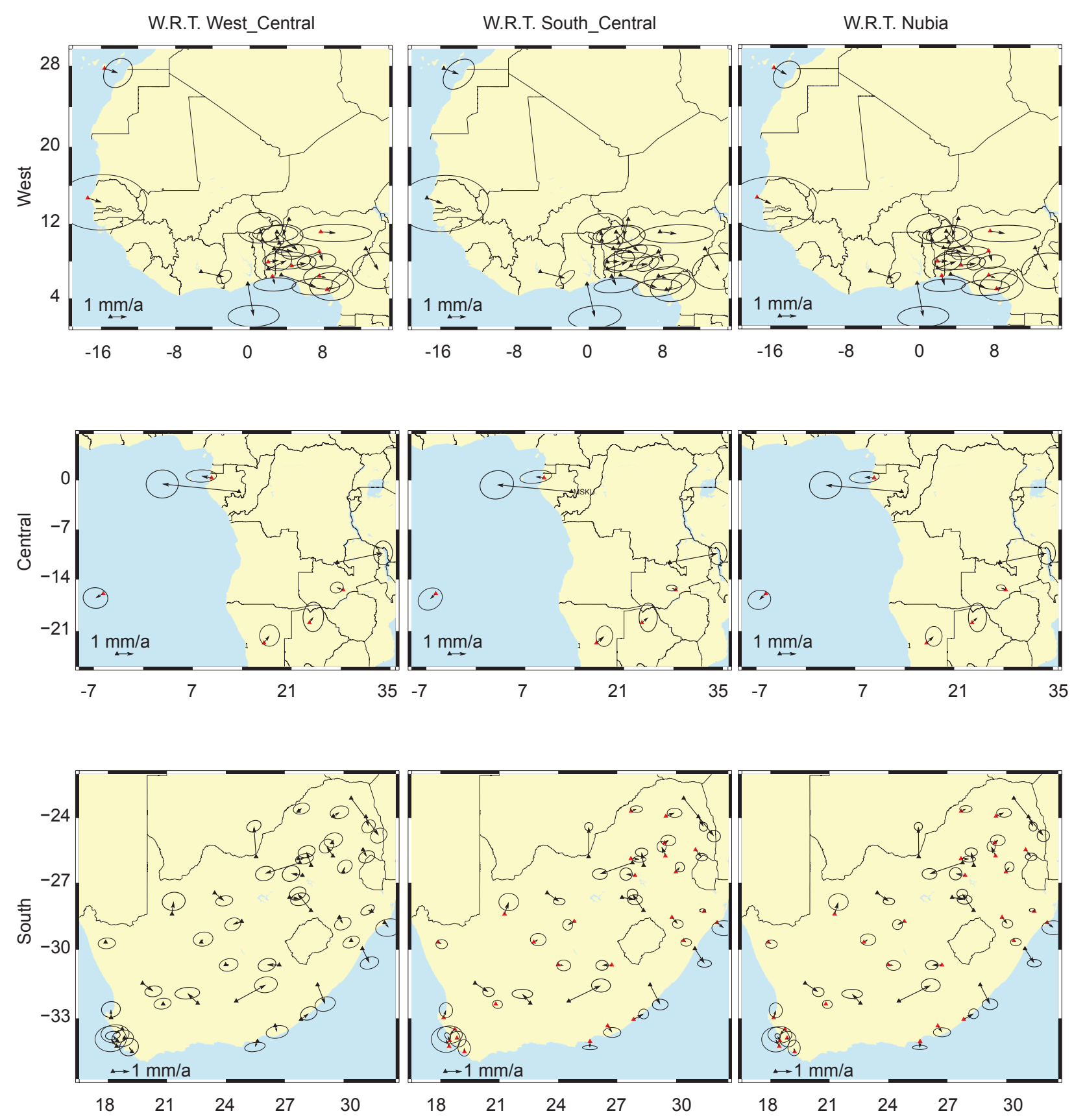

Figure 6:The velocity fields of West, Central and (from top to bottom), with respect to Euler poles South WEST_C, SOUTH_C and NUBIA (from left to right). 

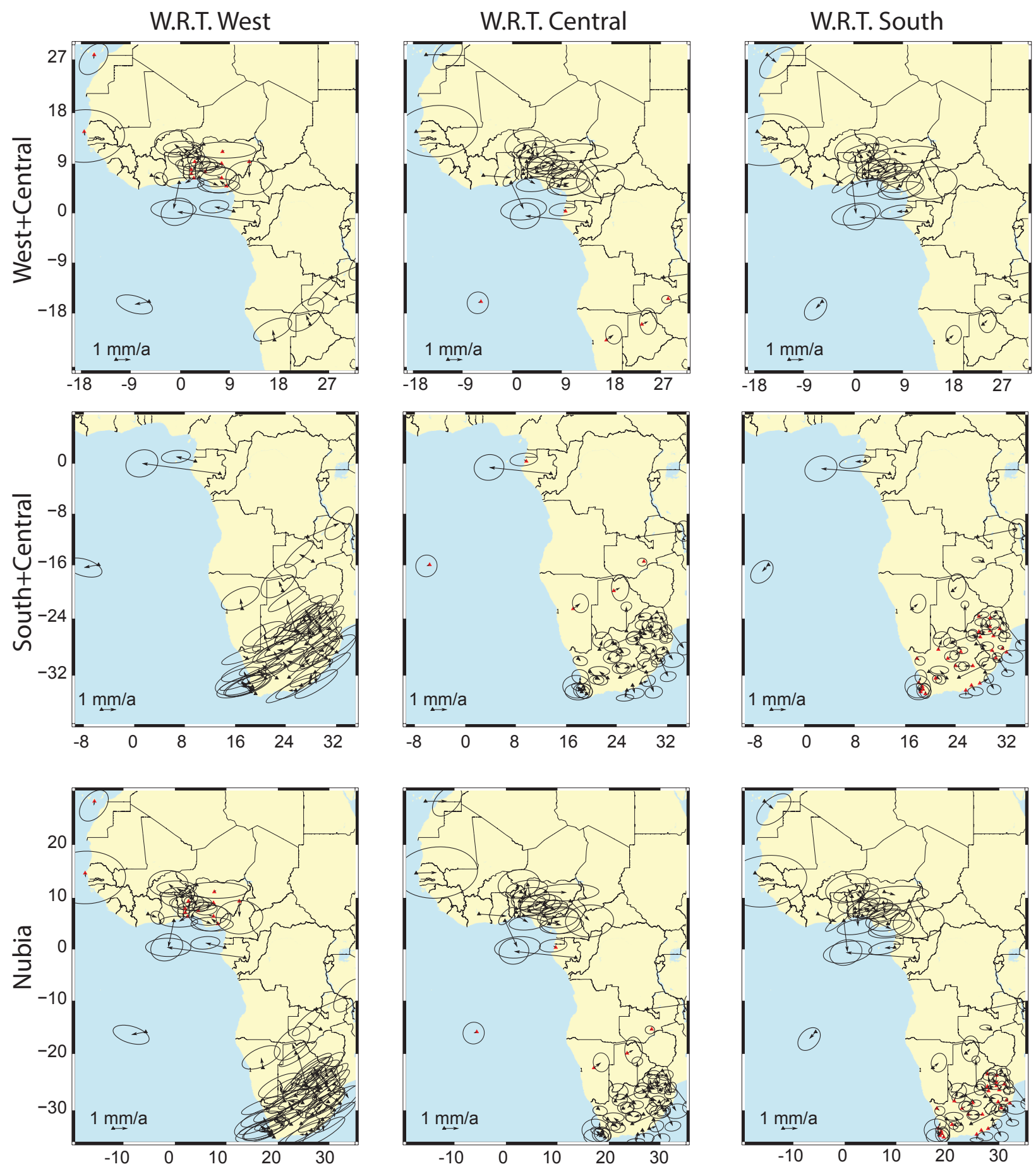

Figure 7: The velocity fields of West-Central (WC), South-Central (SC) and Nubia (NU) (from top to bottom), with respect to WEST, CENTRAL and SOUTH Euler poles (left to right). 

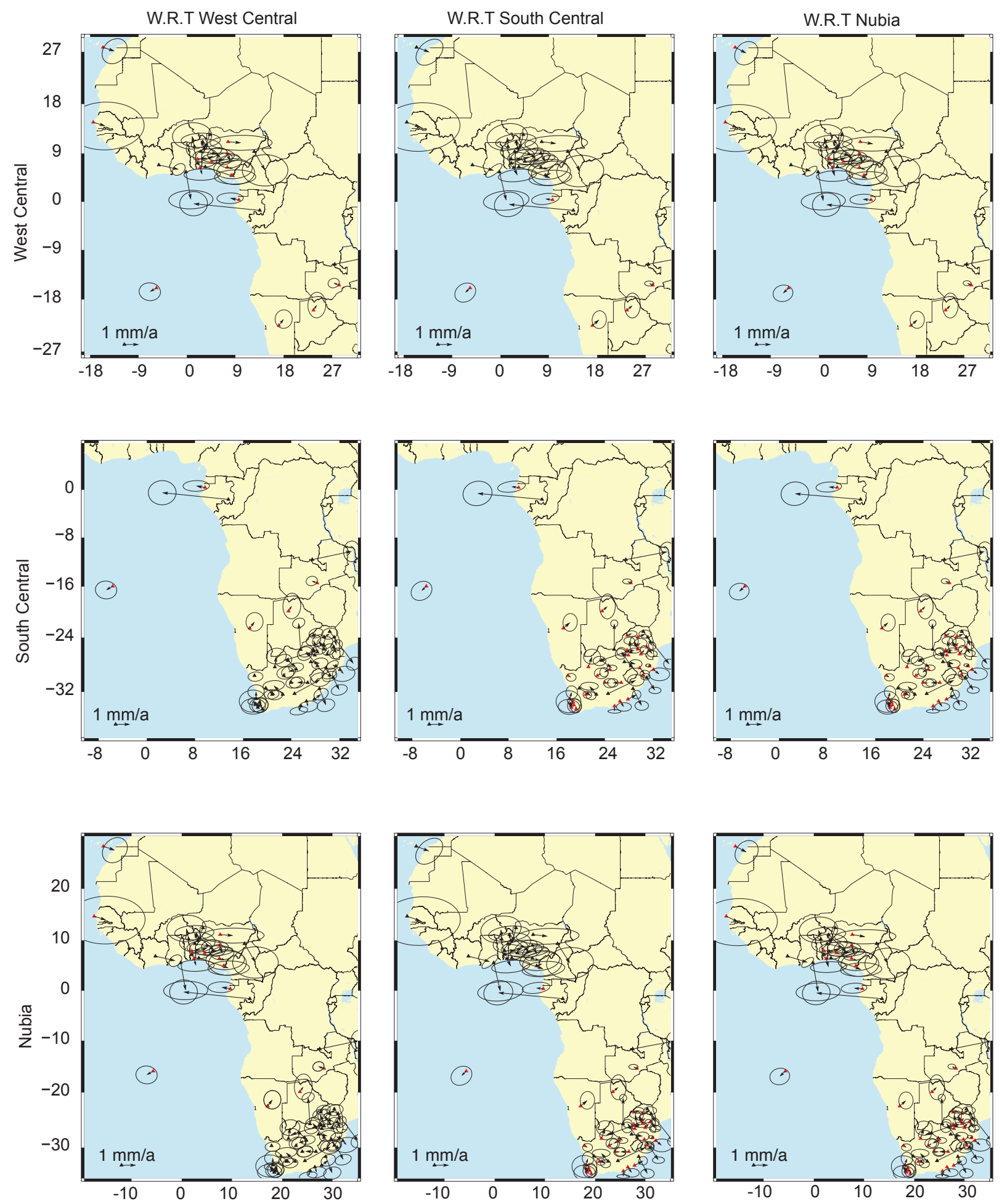

Figure 8:The velocity fields of West-Central, South-Central and Nubia (top to bottom), with respect to WEST_C,SOUTH_C and NUBIA Euler poles. 


\section{CHAPTER FOUR:}

\section{COMPARISON OF EULER VECTORS}

Traditionally, Euler vectors are compared by plotting as separate entities, the position of the Euler pole (with relative error ellipses), and its rate (with relative uncertainties). Since the three components of the Euler vector are highly correlated, it is beneficial to compare the full vectors with the error ellipsoids corresponding to the full covariance matrix (Vanicek and Krakiwsky, 1987). For example, by comparing the six Euler poles calculated in this study using the position of poles and relative error ellipses, it's observed that 5 of them overlap at the $95 \%$ confidence while the WEST Euler pole (Figure 9) is significantly separated from all the other poles. This suggests the possibility of relative motion between the West Africa region and the rest of Nubia. On the other hand, when the full 3D vectors are compared using the full covariance matrix (Figure 10) it's observed that at the $95 \%$ confidence the ellipsoids do touch or overlap, indicating that at the current level of uncertainties it's not possible to rule out rigid plate behavior. The overlap of the error ellipse and ellipsoids also exists at a lower confidence limit (up to 68\%) (Figure 11 and Figure 12) indicating that the likelyhood of rigid plate behavior for the full Nubia plate is significant. Indeed many of the error ellipsoids calculated in the study for the 3 major regions and their combinations are nested within each other and are not fully visible in the figure. This suggests that given current uncertainties and network geometry, the Nubia plate movement with respect to IGb08 is compatible with the motion of a rigid block. 
Further comparison was done where, the Nubia pole of this study was compared with those obtained by Altamimi et al., (2007), Nocquet et al., (2006) and Stamps et al. (2008). While this study Nubia Euler pole does not appear to be compatible with the other two when plotted using error ellipses (Figure 13), using the full 3D vector (Vanicek and Krakiwsky, 1987) and covariance shows that all of the poles are compatible within uncertainities (Figure 14). 


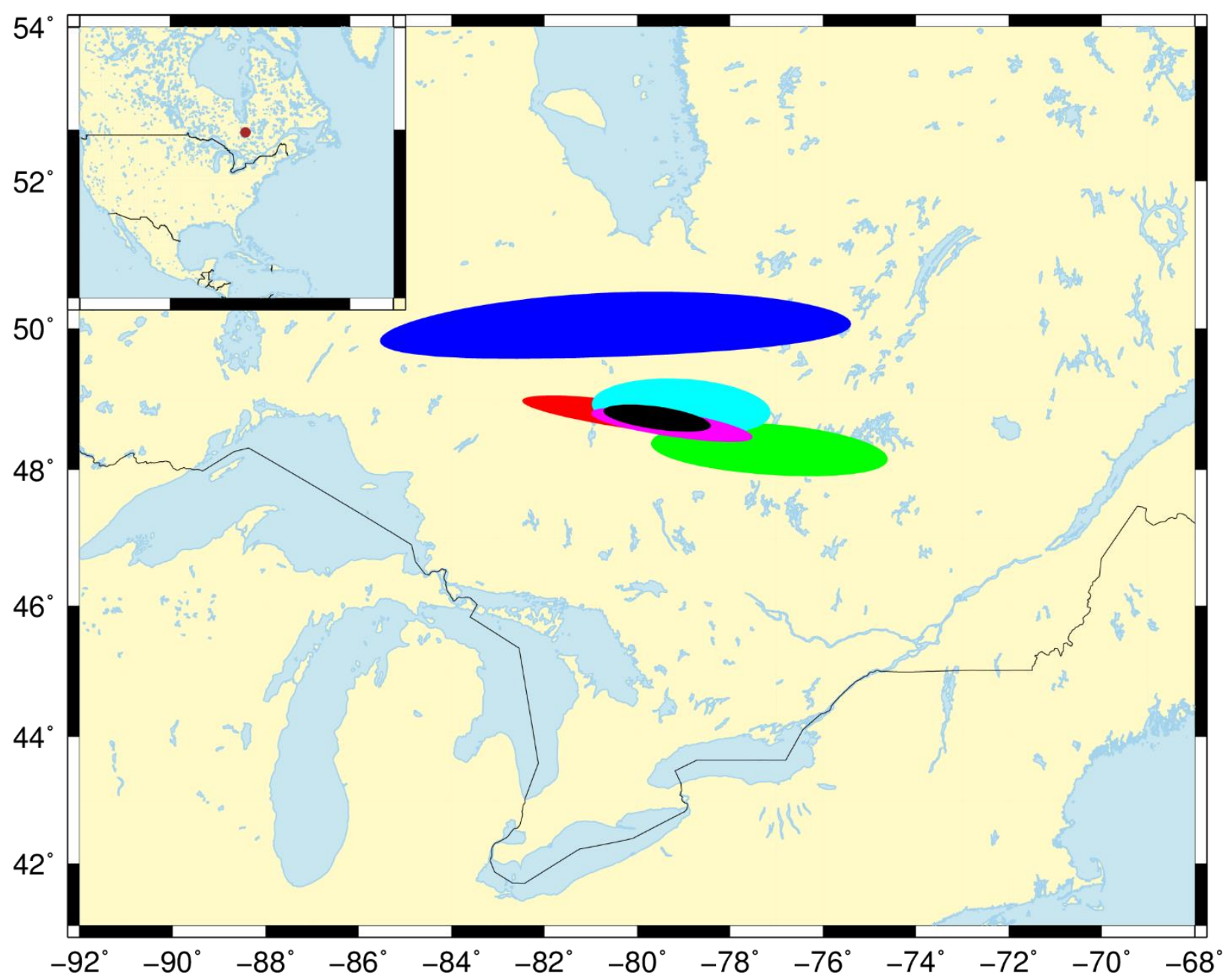

Figure 9: Positions and $2 \sigma$ error ellipses (95\% confidence) of the six Euler poles: WEST (blue), CENTRAL (green), WEST_C(cyan), SOUTH_C (magenta), SOUTH (red), and NUBIA (black) in 2-dimensions, calculated with respect to the IGb08 reference frame. All of the poles except the WEST pole overlap each other. (The brown circle in the inset map shows Euler poles location.) 


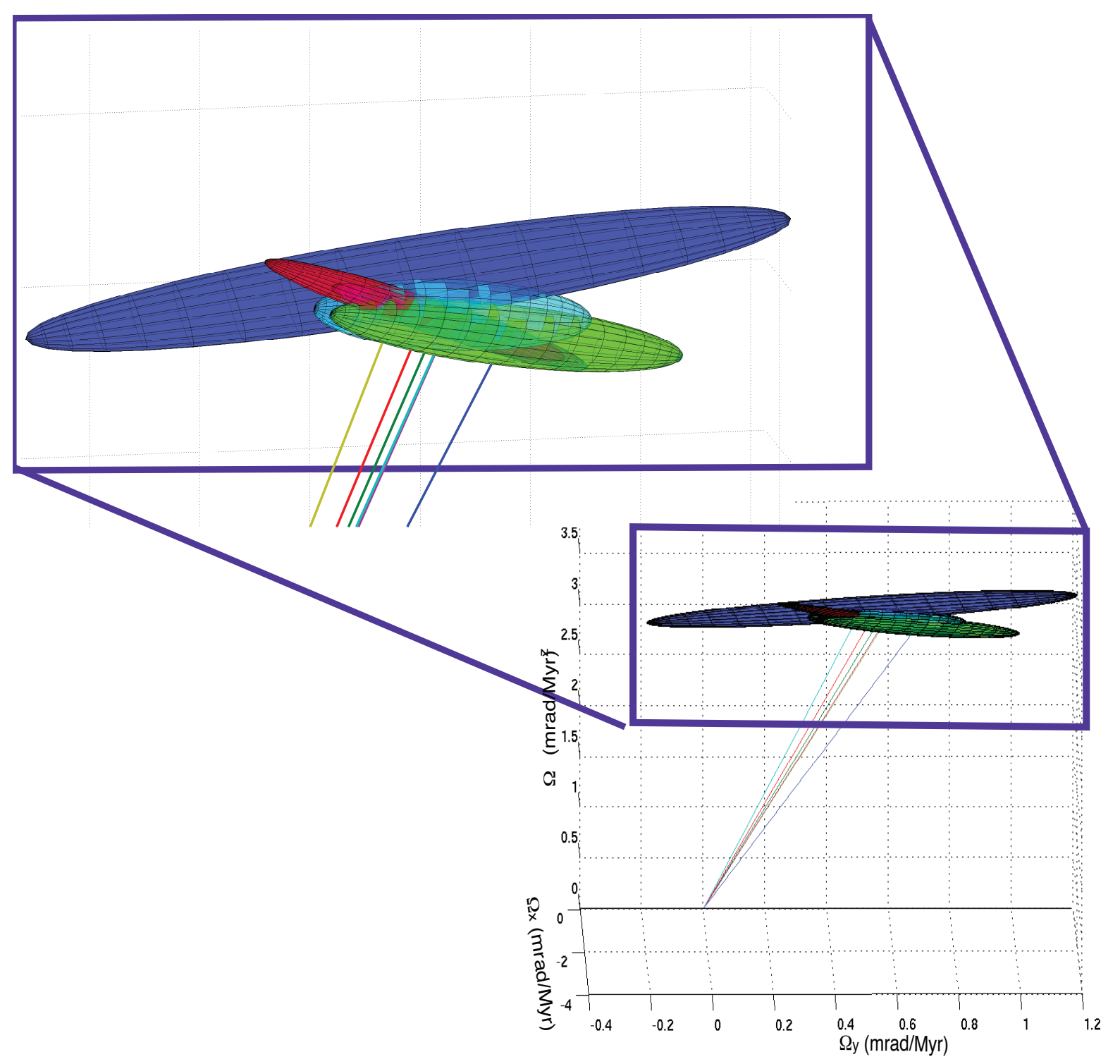

Figure 10: Error ellipsoids (95\% confidence) of the six Euler vectors: WEST (yellow), CENTRAL (red), WEST_C (cyan), SOUTH_C (magenta), SOUTH (blue), and NUBIA (green) in 3-dimensions, calculated with respect to the IGb08 reference frame. All of the Euler vector ellipsoids intersect each other. WEST has the largest ellipsoid while NUBIA and SOUTH_C overlap completely. 


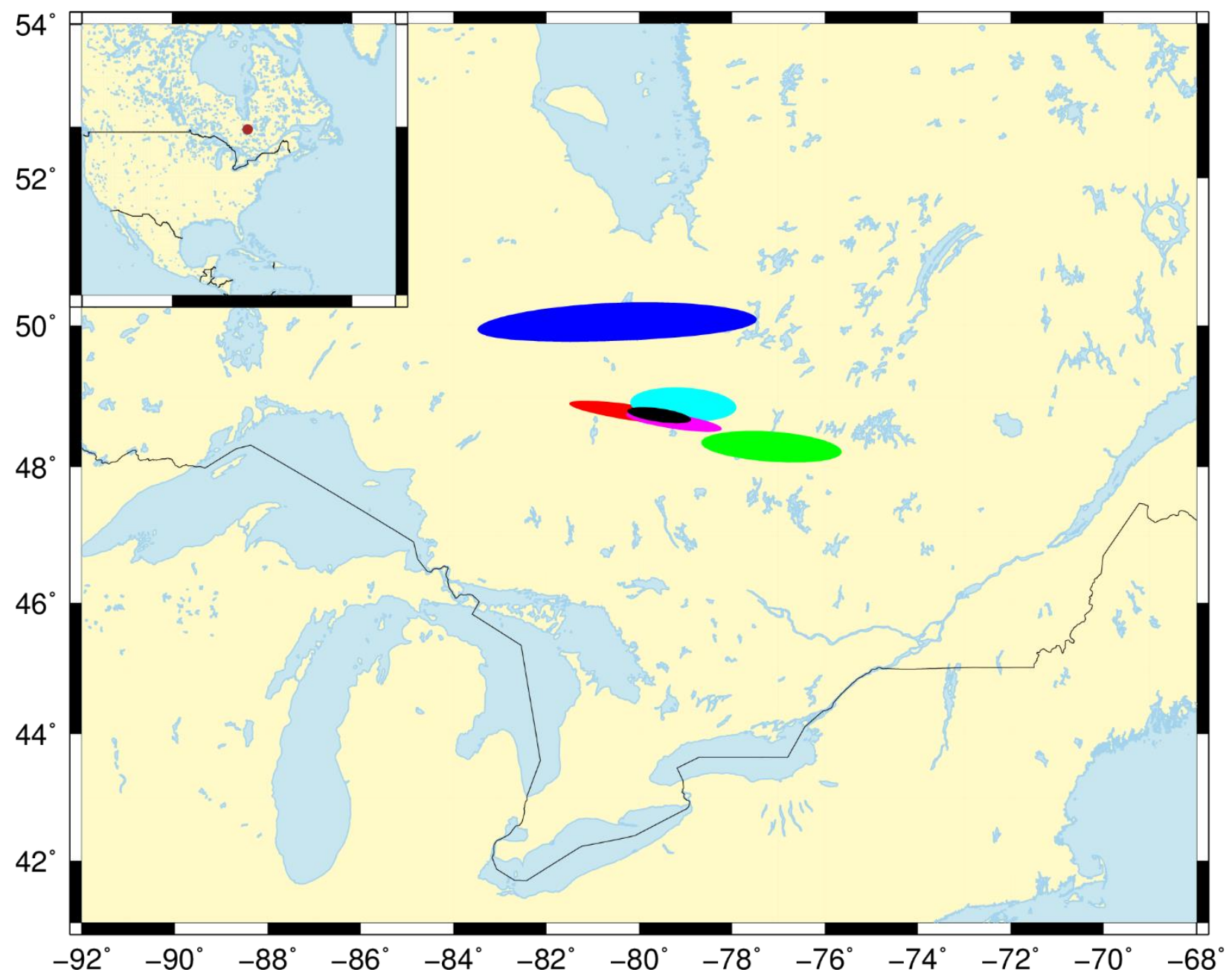

Figure 11: Positions and $2 \sigma$ error ellipses (68\% confidence) of the six Euler poles: WEST (blue), CENTRAL (green), WEST_C(cyan), SOUTH_C (magenta), SOUTH (red) and NUBIA (black) in 2-dimensions, calculated with respect to the IGb08 reference frame. While four error ellipses overlap with each other, WEST pole is significantly separated. (The brown circle in the inset map indicates the location of the Euler poles.) 


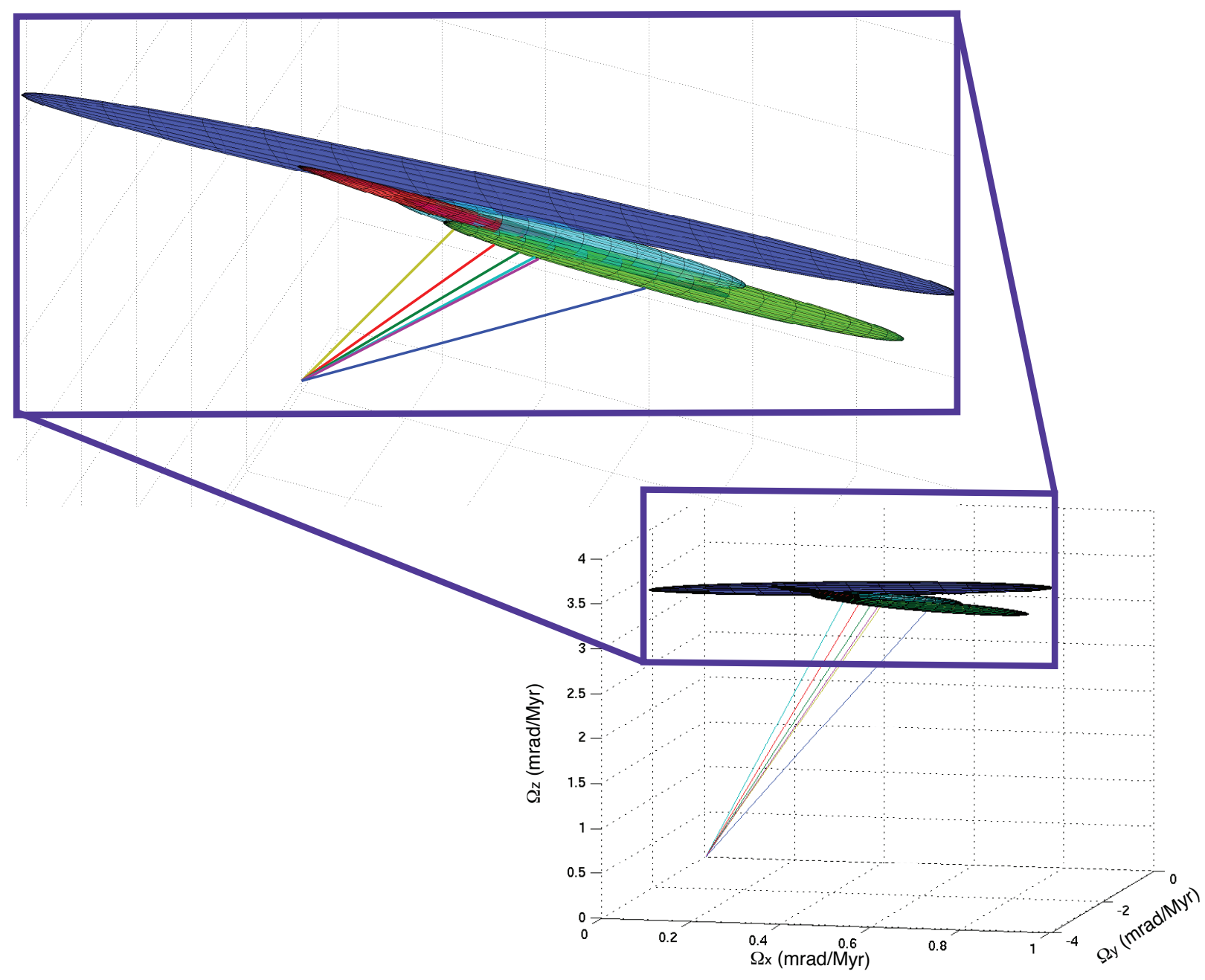

Figure 12: Error ellipsoids (68\% confidence) of six Euler vectors: WEST (yellow), CENTRAL (red), WEST_C (cyan), SOUTH_C (magenta), SOUTH (blue), and NUBIA (green) in three dimensions, calculated with respect to the IGb08 reference frame. All Euler vector ellipsoids intersect each other. WEST has the largest ellipsoid while NUBIA and SOUTH_C overlap completely. 


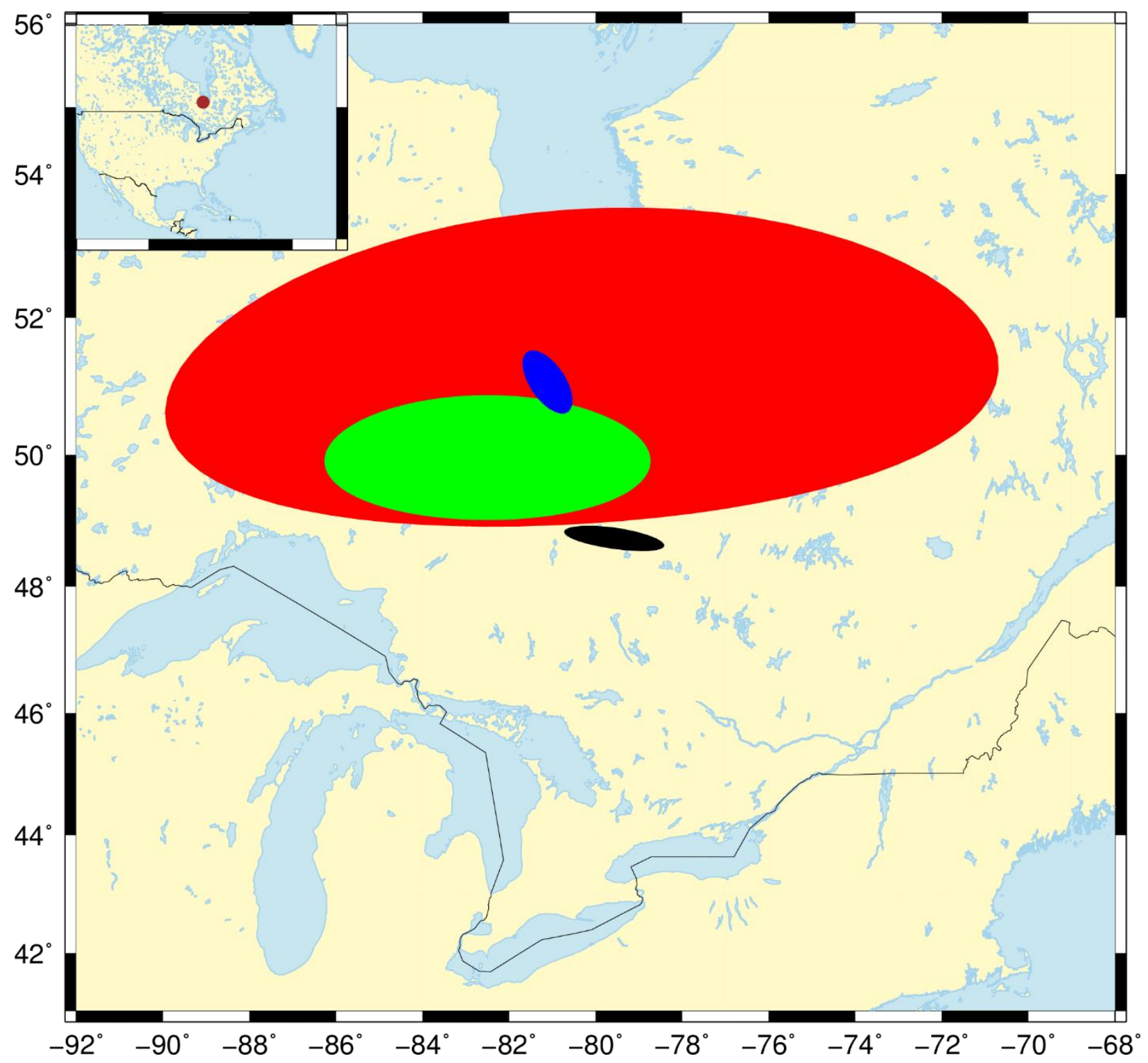

Figure 13: Positions and $2 \sigma$ error ellipses (95\% confidence) of the four Euler poles; Altamimi et al., 2007 (green), Nocquet et al., 2006 (blue), Stamps et al., 2008 (red) and this study (black), calculated with respect to ITRF and IGb08 reference frames. The Present pole does not overlap with the other poles obtained from the most recent studies. (The brown circle in the inset map indicates the location of the Euler poles.) 


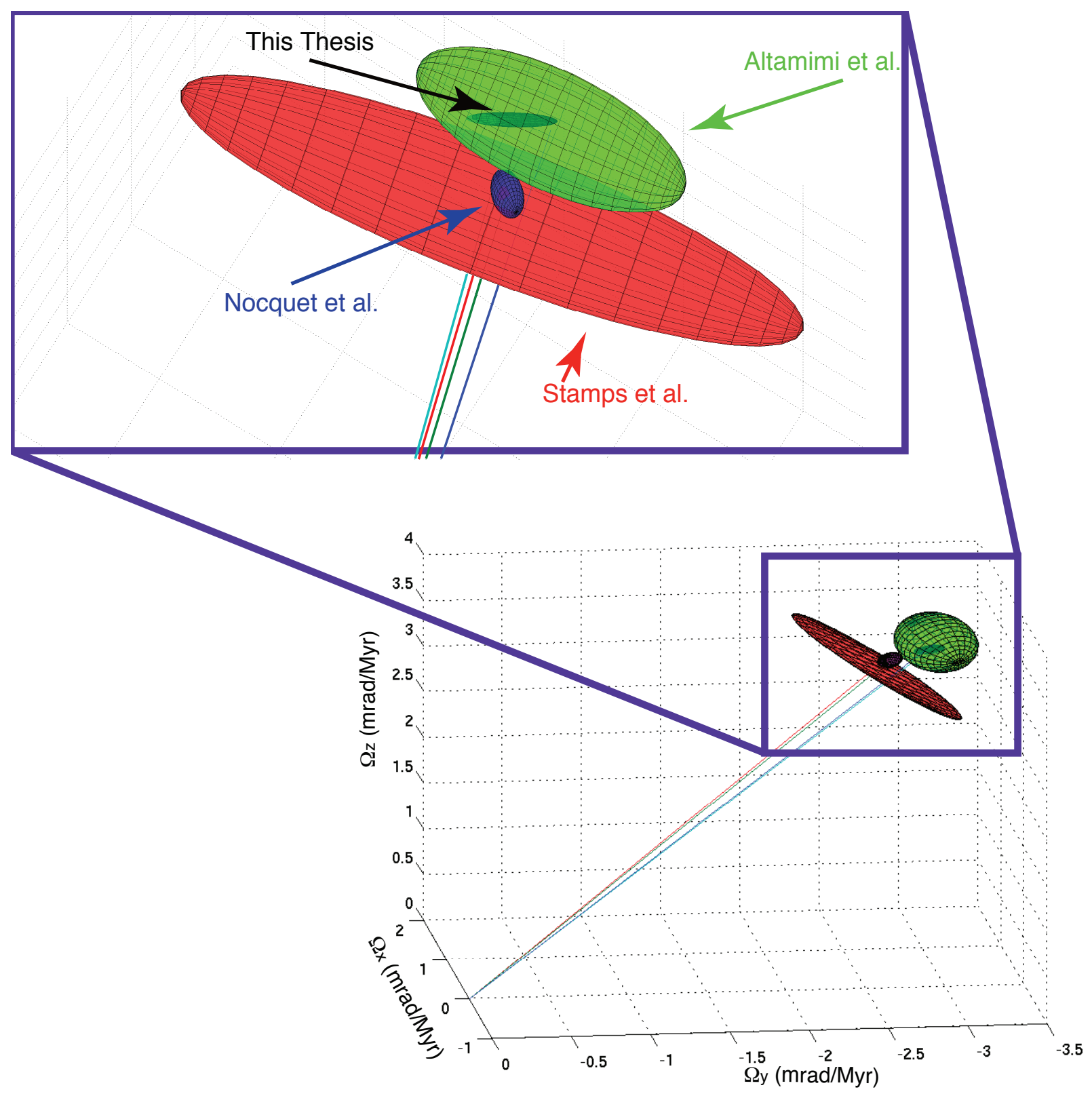

Figure 14: The error ellipsoids (95\% confidence) of the four Euler poles; Altamimi et al. (2007), Nocquet et al. (2006), Stamps et al. (2008) and This Paper, calculated with respect to ITRF and IGb08 reference frames. The four Euler vector ellipsoids are overlapping, with this paper error ellipsoid been completely overlapped by that of Altamimi et al. 2007. 


\section{CHAPTER FIVE:}

\section{ANNUAL SIGNAL AMPLITUDE}

In general, geodetic time series are affected by different periodic signals due to processes related to many different sources, including satellite orbit configuration, seasonal variation of the atmospheric water content, and groundwater storage (Van Dam et al., 2001; Hinderer et al., 2009). These signals strongly affect the accuracy of the estimation of the secular velocity (Van Dam et al., 2001). Bos et al., (2008) demonstrated the effects of these periodic signals on velocity uncertainties, hence the need to put this into consideration in the computation of the errors associated with the secular velocities. The periodic signals are more prominent in the vertical component than in the horizontal components. For example, Blewitt and Lavallee, (2002) and Nahmani et al., (2012) show that the annual signal variation amplitude is about twice as big in the vertical component as in the horizontal components. Since hydrologic and atmospheric signals are probably the main sources of the seasonal variation (Van Dam et al., 2001; Hinderer et al., 2012), it is beneficial to analyze the variation of the annual signal, $b$ (in equation 1 ) as a function of location.

Throughout the full Nubia plate, the annual signal was computed using equation 1.The horizontal components are insignificant and their amplitude ranges between 0.1 and 0.2 $\mathrm{mm}$. The only stations with large variation in the horizontal components are MSKU (in the 
Central network) and KSTD (in the Southern network), which also do not fit the Euler vector rigid motion. However in the vertical component the estimated annual signal amplitude varies from 0.5 to $2.5 \mathrm{~mm}$. The amplitudes in the vertical components also vary regionally and with latitude. In the Southern region, the annual signal has the lowest amplitude, while sites within the Western region and within the Congo and Zambezi basins show the maximum amplitude (Figure 15). Note that the Central part of the West region (latitude $5^{\circ} \mathrm{N}-15^{\circ} \mathrm{N}$ ) is strongly affected by the West Africa Monsoon (WAM) (Bock et al., 2008) and shows an annual signal ranging from 1.5 and $2.5 \mathrm{~mm}$. Also, MAUA, the station in Botswana that shows the second largest annual signal, is within the Okavango river delta, one the largest inland river deltas with large seasonal flooding (McCarthy, 1993). This suggests that hydrological loading plays a major role in the annual variability of the vertical component. The peak of the annual signal for the West network is completely out of phase with the amplitude at MAUA. As already pointed out by Nahmani et al., (2012), the maximum vertical displacement in the West is observed in May, while the minimum vertical displacement is observed in September and is compatible with the inferred total water storage measured by GRACE (eg. Hinderer et al., 2009, 2012; Nahmani et al., 2012; Ramillien et al., 2014). On the contrary, for MAUA and other sites around the Zambezi/Congo rivers, the vertical component of the time series peaks in January and has the lowest point in June, in phase with the hydrological cycle (Crowley et al., 2006; Ramillien et al., 2014). 


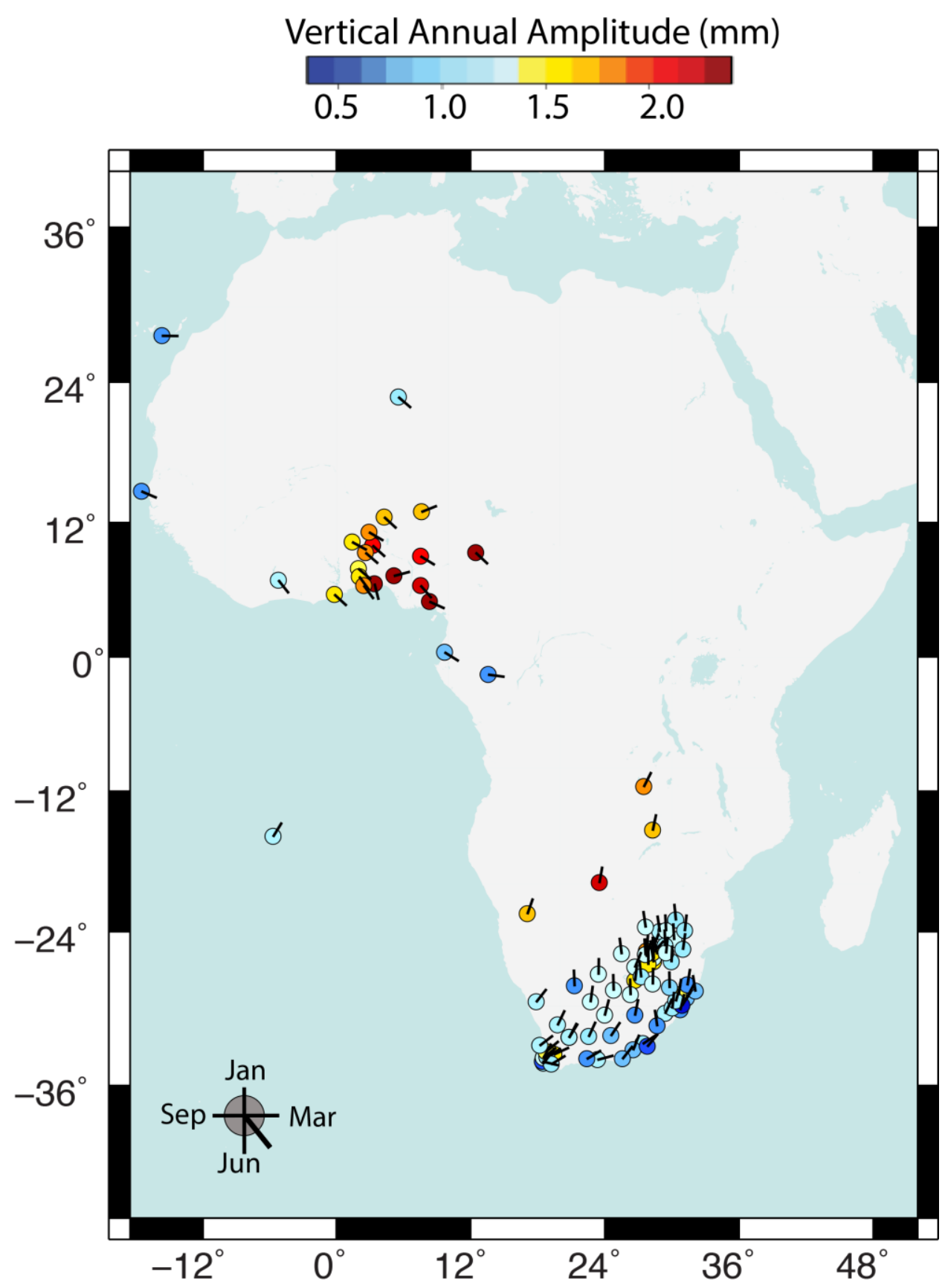

Figure 15. Signal amplitudes of the vertical GPS components of the Nubia plate. The amplitudes vary with latitude: the South region has the smallest amplitudes while the West and Central regions have the largest amplitudes. The lines indicate the phase of the seasonal signal pointing to the North if the peak of the signal is in January and to the South if it is in June. 


\section{CHAPTER SIX:}

\section{NOISE POWER SPECTRUM}

GPS time series are affected by multiple sources of noise including GPS monument stability, antenna problems, multipath, and modeling problems (e.g. troposphere, ionosphere oceanic and atmospheric loading, or orbits) (Johnson and Agnew, 1995; Langbein et al., 1995; Wyatt, 1989; Langbein and Johnson, 1997). Although a full analysis of the noise sources within the network is not in the scope of this study, it's important to point out that many sources of uncertainty in the time series (e.g. multipath, atmospheric loading, tropospheric modeling) are related to the water cycle, and should thus be dependent on latitude. This problem is exacerbated by the fact that seasonal signals are modeled as annual and semiannual signals, even though they are not exactly periodic (e.g. Karegar et al., 2015). This non-periodic variability is included in the noise of velocity calculations.

GPS noise can be categorized into two types: white noise, which is not time-correlated, and colored noise (e.g. flicker and random walk noise), which is time-correlated (Agnew, 1992). Traditionally, colored noise has been calculated as combination of flicker random walk noise or described by as power law spectrum with a spectral index ranging between -2 and 0 (e.g. Agnew,1992; Johnson and Agnew,1995; Williams, 2003; Williams et al., 2004; Amiri-Simkooei et al., 2007; Hackl et al., 2011). Zhang et al., (1997) and Mao et al., 
(1999) also showed that flicker noise (power spectrum of -1) is the primary constituent of colored noise.

The power spectrum of the noise component fitting the Allan variance of rate with white and power law error model (Hackl et al., 2011, 2013) were analyzed. Here, the noise is modeled as a combination of white and power law noise showing that there is no apparent variation of the spectral characteristics. The spectral indices for all three GPS components of the sites within the Nubia plate fall between -0.6 and -1.1 clustering for the majority of the stations between -0.9 and -1.1 (essentially corresponding to flicker noise). It's also noted that the spectral index does not appear to vary geographically, indicating that the variation is more likely related to local effects (as monument type, multipath, or human activities nearby the site) than to latitudinal variation. Instead, as already observed by Hackl et al., (2013), the study shows that the power spectrum helps identify stations that are problematic or affected by transient behavior. Stations like TAMP in the West region, or the stations identified as problematic by Malservisi et al., (2013), all present a spectral index closer to a random walk than to flicker noise. 


\section{CHAPTER SEVEN: \\ DISCUSSION}

Despite geological and geophysical observations suggesting that there is internal deformation within the Nubia plate, the analysis shows that within the current network geometry and uncertainties, the Nubia plate seems to behave like a rigid block, and that the assumption of a rigid Nubia plate would not significantly bias a global reference frame. A comparison of the Euler vectors calculated in this study indicates that the only region that could present relative motion with respect to the rest of the network is the West region. In fact, the ellipsoid corresponding to the Euler vector describing the rigid motion of this region is the only one not nesting with all the others. The difference of this Euler vector with the remaining would allow for some relative motion along the Cameroon volcanic line. Still, it also noted that the WEST Euler vector is the one with the larger uncertainties.

Given the geophysical and geological observation of possible deformation along the Cameroon volcanic line and the Southwestern branch of the EARS, I suggest that a better geometry and denser local network are necessary to identify tectonic signals in those regions. In particular, Northern Africa and the region categorized as Central need a significant improvement of the publicly available datasets.

The analysis also suggests that it is not possible to identify tectonic motion in betterinstrumented areas like the Cape Town region using the current network. This area has 
been affected by different moderate to strong earthquakes over the past 150 years (Fernandez and Guzman, 1979; Theron, 1974), yet the GPS velocity field does not appear to show significant strain accumulation. A more in-depth study of each station taking in account local effects is necessary to possibly identify such signals.

Large reduced $\chi^{2}$ suggests that in the study the uncertainties associated with the secular velocity field were possibly underestimating. In particular, it is possible that the error model chosen (white plus power law plus periodic) is one of the causes of such underestimation, or longer time series are needed to highlight more of the higher correlated noise. For example, it is possible that the periodic signal masks some component of higher spectrum noise (random walk) or that it is necessary to have more degree of freedom for the noise (for example adding a second power law parameter). Large variation of reduced $\chi^{2}$ in the jackknife analysis indicates the possibility of real deformation within the rigid plate that is likely related to local effects rather than to tectonic signals. In particular, GPS are sensitive to periodic and non-periodic signals not incorporated in the analysis based on equation 1 . Time series are affected by both anthropogenic (e.g. mining, agricultural, water extraction, and dams) (e.g. Malservisi et al., 2013) and natural (drought, water cycle, and atmospheric behavior) (e.g. paper on Sierra Nevada rising and Karegar et al., 2015) signals. Although these phenomena are quasi-periodic, an analysis of the signal that is strictly periodic cannot fully correct the time series, and therefore affect the calculation of the secular velocity used for the Euler vector analysis. A detailed analysis similar to Karegar et al., (2015) could improve the ability to separate the different signals and obtain a better understanding of the effects of different components on secular velocity. 


\section{REFERENCES}

Aderemi, A. A.,O. D. Akinyemi1 and A. Adewale (2013), Seismicity Pattern in Southern Africa from 1986 to 2009, Earth Science Research, 2(2), doi:10.5539/esr.v2n2p1

Agnew, D. C. (1992), The time-domain behavior of power-law noises, Geophys.Res.Lett.,19,333-336.

Altamimi, Z., P. Sillard, and C. Boucher (2002), ITRF2000: A new release of the international terrestrial reference frame for earth science applications, J. Geophys. Res., 107(B10), 2214, doi:10.1029/2001JB000561.

Altamimi, Z., X. Collilieux, J. Legrand, B. Garayt, and C. Boucher (2007), ITRF2005: A new release of the international terrestrial reference frame based on time series of station positions and Earth orientation parameters, J. Geophys. Res., 112, B09401, doi:10.1029/2007JB004949.

Altamimi, Z., X. Collilieux, and L. Métivier (2011), ITRF2008: An improved solution of the international terrestrial reference frame, J. Geod., 85(8), 457-473, doi:10.1007/s00190011-0444-4.

Altamimi, Z., L. Metivier, and X. Collilieux (2012), ITRF2008 plate motion model, J. Geophys. Res., 117, B07402, doi:10.1029/2011JB008930.

Amiri-Simkooei, A.R., C. C. J. M. Tiberius and P. J. G. Teunissen (2007), Assessment of noise in GPS coordinate time series: Methodology and results, Journal of Geophysical research, vol. 112, B07413, doi:10.1029/2006JB004913.

Argus D.F. and R.G. Gordon (1996), Tests of the rigid-plate hypothesis and bounds on intraplate deformation using geodetic data from very long baseline interferometry, J. Geophys. Res., 101, 555-572.

Argus D.F., R.G. Gordon, M.B. Heflin, C. Ma,R.J. Eanes, P. Willis, W.R. Peltier and S.E. Owen (2010), The angular velocities of the plates and the velocity of Earth's centre from space geodesy, Geophys. J. Int., 180, 913-960, doi:10.1111/j.1365246X.2009.044463.x.

Begg, G. C., et al. (2009), The lithospheric architecture of Africa: Seismic tomography, mantle petrology and tectonic evolution, Geosphere, 5, 23-50. 
Bennett R. A., S. Hreinsdóttir, M. S. Velasco and N. P. Fay (2007), GPS constraints on vertical crustal motion in the northern Basin and Range, Journal of Geophysical Research Solid Earth , 34, doi: 10.1029/2007GL031515.

Bertiger, W., S.D. Desai, B. Haines, N. Harvey, A.W. Moore, S. Owen and J.P.Weiss (2010), Single receiver phase ambiguity resolution with GPS data. J. Geod. 84 , 327-337, doi:10.1007/s00190-010-0371-9.

Bird, P. (2003), An updated digital model of plate boundaries, Journal of the Earth Sciences 1027, 1525-2027, doi:10.1029/2001GC000252.

Black, R., J. Liegeois (1993), Cratons, mobile belts,alkaline ricks and continental lithospheric mantle: the Pan-Africa testimony, J. of the Geo.Society, London, 150, 89-98.

Blewitt, G. and D. Lavallée (2002), Effect of annual signals on geodetic velocity, J. Geophys. Res., doi: 10.1029/2001JB000570.

Bock, O., et al. (2008), The West African monsoon observed with ground-based GPS receivers during AMMA. J. Geophys. Res. 113, doi : 10.1029/2008JD010327.

Boehm, J., B. Werl, and H. Schuh (2006), Troposphere mapping functions for GPS and very long baseline interferometry from European Centre for Medium-Range Weather Forecasts operational analysis data, J. Geophys. Res., 111, B02406, doi:10.1029/2005JB003629.

Bos, M. S., R.M.S. Fernandes, S.D.P. Williams, and L. Bastos (2008), Fast error analysis of continous GPS observations. Journal of Geodesy, 82(3), 157-166, doi:10.1007/s00190-007-0165-x.

Cahen, L., N. J. Snelling, J. Delhal, and J. R. Vail (1984), The geochronology and evolution of Africa, Clarendon, Oxford,U.K.

Calais E., C. DeMets and J.M. Nocquet (2003), Evidence for a post-3.16 -Ma change in Nubia-Eurasia-North America plate motions?, Earth and Planetary Science Letters, 216, 81-92.

Calais, E., C. J. Ebinger, C. Hartnady, and J. M. Nocquet (2006), Kinematics of the East African Rift from GPS and earthquake slip vector data, in The Afar Volcanic Province Within the East African Rift System, vol. 259, edited by G. Yirgu, C. J. Ebinger, and P. K. H. Maguire, pp. 9-22, Geol. Soc. Spec. Publ., London, U. K.

Chase, C. G. (1972), The n-plate problem of plate tectonics, Geophys. J. R. astr. SOC., 29, 117-122.

Chase, C. G. (1978), Plate kinematics: The Americas, East Africa, and the rest of the world, Earth planet. Sci. Lett., 37,355-368.

Chorowicz, J. (2005), The East African rift system, Journal of African Earth Sciences 43, 379-410. 
Chu, D., and R. Gordon (1999), Evidence for motion between Nubia and Somalia along the Southwest Indian Ridge, Nature, 398, 64-66.

Condie, K. C., (1994), Archean crustal evolution, Elsevier Sci., New York.

Cretaux, J., L. Soudarin, A. Cazenave and F. Bouil (1998), Present-day tectonic plate motions and crustal deformations from the DORIS space system, Geophys. REs. Lett., 130,167-30.

Crowley, J.W., J.X. Mitrovica, R.C. Bailey, M.E. Tamisiea, J.L. Davis (2006). Land storage within the Congo Basin inferred from GRACE satellite gravity data, Geophys. REs. Lett., 33, L19402, doi:10.1029/2006GL027070.

Delvaux, D., and A. Barth (2009), African stress pattern from formal inversion of focal mechanism data, Tectonophysics, 482, 105-128, doi: 10.1016/j.tecto.2009.05.009.

DeMets, C., R.G. Gordon, D.F. Argus and S. Stein (1990), Current plate motions. Geophys. J. Int. 101, 425- 478.

Déprez, A., C. Doubre, F. Masson, and P. Ulrich (2013), Seismic and aseismic deformation along the East African Rift System from a reanalysis of the GPS velocity field of Africa, Geophys. J. Int., 193, 1353-1369, doi:10.1093/gji/ggt085.

De Wit,M.J., E.J.D. Cornel, M. Tredoux, C. Roering, R. J. Hart, R. A. Armstrong, R. W. E. Green, E. Peberdy and R. A. Hart (1992), Formation of an Archaean continent, Nature 357, 553-562, doi:10.1038/357553a0.

De Wit, M., J. Stankiewicz and C. Reeves (2008), Restoring Pan-African Brasiliano connections: more Gondwana control, less Trans-Atlantic corruption, Geological Society, London, Special Publications, Vol. 294, pp. 399-412, doi:10.1144/SP294.20.

Dixon T.H., A. Mao and S. Stein (1996), How rigid is the stable interior of the North American plate?, Geophys. Res. Let., 23,3035-3038.

Eagles, G. (2007), New angles on South Atlantic opening, Geophys. J. Int., 168, 353361.

Ebinger, C. (1989), Tectonic development of the western branch of the East African Rift System, Geol. Soc. Am. Bull., 101, 885-903.

Fernandes, R.M.S., B.A.C. Ambrosius and R. Noomen (2003), The relative motion between Africa and Eurasia as derived from ITRF2000 and GPS data, Geophysical Research Letters, 30, 16 doi:10.1029/2003GL017089. 
Fernandes, R.M.S, B.A.C. Ambrosius, R. Noomen, L. Bastos, L. Combrinck, J. Miranda and W. Spakman (2004), Angular velocities of Nubia and Somalia from continuous gps data: implications on present-day relative kinematics, Earth planet. Sci. Lett., 222, 197208, doi:10.1016/j.epsl.2004.02.008.

Fernandes R.M.S., J.M. Miranda, D.Delvaux, D.S.Stamps and E.Saria (2013), Reevaluation of the kinematics of Victoria block using continuous GNSS data, Geophys. J. Int.,doi:10.1093/gji/ggs071.

Fernandez L.M. and J.A. Guzman (1979), Seismic history of Southern Africa, Geol. Surv. S. Afr., Seism, Ser. 9,78pp.

Goldstein, H. (1950), Classical Mechanics. Addison Wesley, Cambridge, MA, 399 pp.

Gordon, R.G. (1998). The plate tectonic approximation: plate nonrigidity, diffuse plate boundaries, and global plate reconstructions, Annu. Rev. Earth planet. Sci., 26, 615-642.

Hackl, M., R. Malservisi, U. Hugentobler and R. Wonnacott (2011), Estimation of velocity uncertainties from GPS time series: examples from the analysis of the South African TrigNet network, J. geophys. Res., 116, B11404, doi:10.1029/2010JB008142.

Hackl, M., R. Malservisi, U. Hugentobler and Y. Jiang (2013), Velocity covariance in the presence of anisotropic time correlated noise and transient events in GPS time series , Journal of geodynamics, 72, 36-45.

Hartnady, C. J. H. (1990), Seismicity and plate boundary evolution in southeastern Africa, S. Afr. J. Sci., 93, 473-484.

Hartnady, C. J. H. (2002), Earthquake hazard in Africa: Perspectives on the NubiaSomalia boundary, S. Afr. J. Sci., 98, 425-428.

Hinderer et al. (2009), The GHYRAF (Gravity and Hydrology in Africa) experiment: Description and first results Journal of Geodynamics 48, 172-181.

Hoffman, P.F. (1999), The break-up of Rodinia, birth of Gondwana, true polar wander and the snowball Earth, Journal of African Earth Sciences, 28, 1733.

Horner-Johnson, B. C., R. G. Gordon, S. M. Cowles, and D. F. Argus (2005), The angular velocity of Nubia relative to Somalia and the location of the Nubia-Somalia-

Antarctica triple junction, Geophys. J. Int., 162, 221-238, doi:10.1111/j.136524X.2005.02608.x.

Horner-Johnson, B. C., R. G. Gordon, and D. F. Argus (2007), Plate kinematic evidence for the existence of a distinct plate between the Nubia and Somalian plates along the Southwest Indian Ridge, J. Geophys. Res., 112, B05418, doi:10.1029/2006JB004519. 
Jestin, F., P. Huchon, and J. M. Gaulier (1994), The Somali plate and the East African Riftsystem: Present-day kinematics, Geophys. J. Int., 116, 637-654.

Johnson, H. and D.C. Agnew (1995), Monument motion and measurements of crustal velocities, Geophys.Res.Lett.,22, 2905-2908.

Karegar, M., T.H. Dixon, and R. Malservisi (2015), A three-dimensional surface velocity for the Mississippi Delta: Implications for Coastal restoration and flood potential, Geological Society of America, doi:10.1130/G36598.1

Krabbendam, M and T.D. Barw (2000), Proterozoic orogens and the break-up of Gondwana: why did some orogens not rift? Journal of African Earth Sciences, 31, 35-49.

Kreemer, C., W. E. Holt, and A. J. Haines (2003), An integrated global model of presentday plate motions and plate boundary deformation, Geophys. J. Int., 154, 8-34.

Langbein, J., D. Dzurisin, G. Marshall, R. Stein, and J. Rundle (1995), Shallow and peripheral volcanic sources of inflation revealed by modeling two-color geodimeter and leveling data from Long Valley Caldera, California, 1988-1992, J. Geophys. Res., 100, 12,487-12,495.

Langbein, J., and H. Johnson (1997), Correlated errors in geodetic time series: Implications for time-dependent deformation, J. Geophys. Res., 102,591-603.

Lemaux, J., R. G. Gordon, and J.-Y. Royer (2002), The location of the Nubia-Somalia boundary along the Southwest Indian Ridge, Geology, 30, 339-342.

Le Pichon X. (1968) Sea-floor spreading and continental drift. J. Geophys. Res. 73:366197.

Lichten, S. and J. Border (1987), Strategies for high-precision Global Positioning System orbit determination, Journal of Geophysical Research: Solid Earth, 192, 12751-12762, doi: 10.1029/JB092iB12p12751.

Lyard, F., F. Lefevre, and T. Letellier (2006), Modelling the global ocean tides: Modern insights from FES2004, Ocean Dyn.,56(5-6), 394-415, doi:10.1007/s10236-006-0086x.

Malservisi, R., U. Ugentobler, R. Wonnacott, and M. Hackl (2013), How rigid is a rigid plate? Geodetic constraint from the TrigNet CGPS network, South Africa, Geophys. J. Int., 192, 918-928, doi:10.1093/gji/ggs081.

Malservisi, R., S.Y. Schwartz, N. Voss, M. Protti, V. Gonzales, T.H. Dixon, Y. Jiang, A.V. Newman, J.A. Richardson, J.I. Walter, and D. Voytenko (2015), Multiscale postseismic behavior on a megathrust: the 2012 Nicoya earthquake, Costa Rica, Geochem. Geophys. Geosyst., 16, doi:10.1002/2015GC005794.

Mao, A. L., C. G. A. Harrison, and T. H. Dixon (1999), Noise in GPS coordinate timeseries,J. Geophys.Res.,104,2797-2816. 
McCarthy, T.S. (1993) The great inland deltas of Africa, J. of African Earth Scie., 17(3), 275-291.

McClusky, S., R. Reilinger, S. Mahmoud, S. Ben D., and A. Tealeb (2003), GPS constraints on Africa (Nubia) and Arabia plate motions, Geophys. J. Int., 155, 126-138, doi:10.1046/j.1365-246X.2003.02023.

McKenzie, D. P., D. Davies and P. Molnar (1970), Plate tectonics of the Red Sea and East Africa, Nature 226, 243-248.

McKenzie, D. and R. Parker (1967), The North Pacific: an example of tectonics on a sphere, Nature, 216, 1276-1280.

McKenzie, D. and J.G. Sclater (1971), The evolution of the Indian Ocean since the Late Cretaceous. Geophysical Journal of Royal Astronomical Society 25 (5), 437-528.

Midzi, V., D. Hlatywayo, L. Chapola, F. Kebede, K. Atakan, D. Lombe, G. Turyomurugyendo and F. Tugume (1999), Seismic hazard assessment in Eastern and Southern Africa, Annali di Geofisica, 42, 1067-1083.

Minster, J.B., T.H. Jordon, P. Molnar and E. Haines (1974), Numerical modelling of instantaneous plate tectonics, Geophys. J. R. astr. Soc.,36,541-576.

Minster, J. B. and T.H. Jordan (1978), Present-day plate motions, J. geophys. Res., 83, 5331-5354.

Modisi, M.P. (2000), Fault system of the southeastern boundary of the Okavango Rift, Botswana, J. Afr. Earth Sci., 30, 569-578.

Morgan, W.J. (1968), Rises, trenches, great faults and crustal blocks. Journal of Geophysical Research 73 (6), 1959-1982.

Nahmani, S., O. Bock, M. Bouin, A. Santamaría-Gómez, J. Boy, X. Collilieux, L. Métivier, I. Panet, P. Genthon, C. de Linage and G. Wöppelmann (2012), Hydrological deformation induced by the West African Monsoon: Comparison of GPS, GRACE and loading models, Journal of Geophysical research, vol. 117, b05409, doi:10.1029/2011jb009102.

Nemčok,M., A. Henk, R. Allen, P. J. Sikora and C. Stuart (2012), Continental break-up along strike-slip fault zones; observations from the Equatorial Atlantic, Geological Society, doi:10.1144/SP369.8.

Nocquet, J. M., P. Willis, and S. Garcia (2006), Plate kinematics of Nubia-Somalia using a combined DORIS and GPS solution, J. Geod., 80, 591-607.

Nusbaum, R. L., R. W. Girdler, J. R. Heirtzler, D. J. Hutt, D. Green, V. E.Millings, B. S. Schmoll, and J. Shapiro (1993), The distribution of earthquakes and volcanoes along the East African Rift system,16, 427-432. 
Nyblade, A. A. and C. A. Langston (1995), East African earthquakes below $20 \mathrm{~km}$ depth and their implications for crustal structure, Geophys. J. Int., 121, 49-62.

Pitman, W.C. and M. Talwani (1972), Seafloor spreading in the North Atlantic. Geological Society of America Bulletin 83, 619-646.

Plattner,C., R. Malservisi, T. H. Dixon, P. LaFemina, G. F. Sella, J. Fletcher and F. Suarez-Vidal (2007), New constraints on relative motion between the Pacific Plate and Baja California microplate (Mexico) from GPS measurements, Geophys. J. Int. doi: 10.1111/j.1365-246X.2007.03494.X.

Prawirodirdjo, L., and Y. Bock (2004), Instantaneous global plate motion model from 12 years of continuous GPS observations, J. Geophys. Res., 109, B08405, doi:10.1029/2003JB002944.

Ramillien, G., F. Frappart, L. Seoane (2014). Application of the regional water mass variations from GRACE satellite gravimetry to large scale water management in Africa, Remote Sens. 6, 7379-7405, doi:10.3390/rs6087379.

Rebischung, P., J. Griffiths, J. Ray, R. Schmid, X. Collilieux and B. Garayt (2011), IGS08: the IGS realization of ITRF2008, GPS Solut, 16, 483-494 DOI 10.1007/s10291011-0248-2.

Reeves, C. (1999), Aeromagnetic and gravity features of Gondwana and their relation to continental break-up: more pieces, less puzzle, J. Afr. Earth Sci., 28, 263-277.

Reeves, C. and M. De Wit (2000), Making ends meet in Gondwana: retracting the transforms of the Indian Ocean and reconnecting continental shear zones, Terra Nova, $12,272-280$.

Reeves, C., M. De Wit and B. Sahu (2004), Tight reassembly of Gondwana exposes phanerozoic shears in Africa as global tectonic players, Gondwana Res., 7, 7-19.

Roberts, E. M., N. J. Stevens, P. M. O'Connor, P. H. G. M. Dirks, M. D. Gottfried, W. C. Clyde, R. A. Armstrong, A. I. S. Kemp, and S. Hemming (2012), Initiation of the Western branch of the East African Rift coeval with the Eastern branch, Nat. Geosci., 5(4), 289294, doi:10.1038/ngeo1432.

Saria, E., E. Calais, Z. Altamimi, P. Willis, and H. Farah (2013), A new velocity field for Africa from combined GPS and DORIS space geodetic solutions: Contribution to the definition of the African reference frame (AFREF), J. Geophys. Res. Solid Earth, 118, 1677-1697, doi:10.1002/jgrb.50137.

Saria, E., E.Calais,D., S.Stamps, D.Delvaux and C.J.H.Hartnady, (2014), Present-day kinematics of the East African Rift, J. Geophys. Res. Solid Earth, doi: 10.1002/2013JB010901. 
Selesnick, I. W., S. Arnold, and V. R. Dantham (2012), Polynomial Smoothing of Time Series With Additive Step Discontinuities, IEEE Trans. Signal Processing, 60(12):63056318.

Sella, G. F., T. H. Dixon, and A. Mao (2002), REVEL : A model for recent plate velocities from space geodesy, J. Geophys. Res., 107, 2081, doi:10.1029/2000JB00033.

Sella, G.F., S. Stein, T.H. Dixon, M. Craymer, S. James, S. Mazzotti and R.K. Dokka (2007), Observation of glacial isostatic adjustment in 'stable' North America with GPS, Geophys. Res. Lett., 34 (L02306), doi:10.10292006GL027081.

Shemang, E. and L. Molwalefhe (2011), Geomorphic landforms and tectonism along the eastern margin of the Okavango Rift Zone, Northwestern Botswana, as deduced from geophysical data,in New Frontiers in Tectonics Research, General Problems, Sedimentary Basins, and Island Arcs, pp. 169-182, ed. Sharkov, E., Intechopen.

Stamps, D. S., E. Calais, E. Saria, C. Hartnady, J. M. Nocquet, C. Ebinger, and R. Fernandez (2008), A kinematic model for the East African Rift, Geophys. Res. Letters,35, L05304, doi:10.1029/2007GL032781.

Stein, S., and R. G. Gordon (1984), Statistical tests of additional plate boundaries from plate motion inversions, Earth planet. Sci. Lett., 69, 401-412.

Theron J.N. (1974), The seismic history of the SouthWestern cape province, Geol. Surv. S. Afr., Seism, Ser. 12-18.

Tregoning P., T. van Dam, (2005), Atmospheric pressure loading corrections applied to GPS estimates of station heights and zenith total delays, Geophys. Res. Lett., 33, L23303, doi:10/1029/2006GL02770.

van Dam, T. M., G. Blewitt, and M. B. Heflin (1994), Atmospheric pressure loading effects on Global Positioning System coordinate determinations, J. Geophys. Res., 99, 23,939 23,950 .

van Dam, T., J. Wahr, P. C. D. Milly, A. B. Shmakin, G. Blewitt, D. Lavall'ee and K. M. Larson (2001), Crustal displacements due to continental water loading, Geophysical Res. Lett. 28, 651-654.

Vanicek P. and E. Krakiwsky (1987), Geodesy: The Concepts, 2nd edn. Elsevier Science.

Williams, S. D. P. (2003), The effect of coloured noise on the uncertainties of rates estimated from geodetic time series, J.Geod., 76, 483-494, doi: 10.1007/s00190-0020283-4.

Williams, S. D. P., Y. Bock, P. Fang, P. Jamason, R. M. Nikolaidis, L. Prawirodirdjo, M. Miller, and D. J. Johnson (2004), Error analysis of continuous GPS time series, J. Geophys. Res., 109, B03412, doi: 10.1029/2003JB002741. 
Wyatt, F. (1989), Displacements of surface monuments: Vertical motion, J.Geophys.Res.,94,1655-1664.

Zhang, J., Y. Bock, H. Johnson, P. Fang, J. F. Genrich, S. Williams, S. Wdowinski, and J. Behr (1997), Southern California permanent GPS geodetic array: Error analysis of daily position estimates and site velocities,J.Geophys.Res.,102,18,035-18,055.

Zumberge, J.F., M. Heflin, D. Jefferson, M. Watkins and F. Webb (1997). Precise point positioning for the efficient and robust analysis of GPS data from large networks. Journal of Geophysical Research: Solid Earth, doi: 10.1029/96JB03860. 


\section{APPENDIX 1}

Mathematical Formulation for the Inverse Problem to Find the Best Fitted Euler Vector

Based on the Euler theorem, every motion of a rigid body on the surface of a sphere can be described as a rotation around an axis passing through the center of the sphere. The intersection of this axis with the surface of the sphere is commonly called Euler pole. Thus if we want to describe the motion of a rigid body on a sphere it is enough to specify the Euler pole and the magnitude of the rotation. It is also possible to describe the rotation as a vector (the Euler vector) that has by definition the direction of the axis of rotation and as magnitude the angle of the rotation.

The description of the motion of plate $A$ with respect to plate $B$ can thus be specified by an Euler pole or an Euler vector ${ }_{A} \vec{\Omega}_{B}$

$$
{ }_{A} \vec{\Omega}_{B}=[\text { Lat, Lon, Magnitude }] \text { or }\left[\Omega_{x}, \Omega_{y}, \Omega_{z}\right]
$$

In general is normal to express the Magnitude of the Euler vector in $\left[\frac{\circ}{M y r}\right]$ and the components of the vector in $\left[\frac{\mathrm{rad}}{\mathrm{Myr}}\right]$.

Given the Euler pole [Lat; Lon; $\square$ ] (where $\square$ is the magnitude of the vector) it is possible to compute the components of the Euler vector using spherical coordinates obtaining: 


$$
\left\{\begin{array}{c}
\Omega_{x}=\Omega \cos (\text { Lat }) \cos (\text { Lon }) \\
\Omega_{y}=\Omega \cos (\text { Lat }) \sin (\text { Lon }) \\
\Omega_{z}=\Omega \sin (\text { Lat })
\end{array}\right.
$$

Given the position of a point $\mathrm{P}$ on the surface of the Earth with coordinates Latp and Lon it is always possible to define a vector $\vec{R}$ pointing from the center of the Earth (the origin of our coordinates system) to the location of the point on the surface of the Earth

$$
\left\{\begin{aligned}
\mathrm{R}_{x}= & R_{E} \cos \left(\text { Lat }_{P}\right) \cos \left(\text { Lon }_{P}\right) \\
\mathrm{R}_{y}= & \mathrm{R}_{E} \cos \left(\text { Lat }_{P}\right) \sin \left(\text { Lon }_{P}\right) \\
& \mathrm{R}_{z}=\mathrm{R}_{E} \sin \left(\text { Lat }_{P}\right)
\end{aligned}\right.
$$

Where $R_{E}$ is the radius of the Earth (since the Eulerian theorem works on a sphere all this theory is based on a spherical Earth so we use $R_{E}=6371 \mathrm{~km}$ that is the radius of a sphere that has the same volume of our planet).

The velocity of the motion described by the Eulerian vector for every point $\mathrm{P}$ on the sphere is calculated using the formula:

$$
\overrightarrow{V_{P}}={ }_{A} \vec{\Omega}_{B} \times \vec{R}_{p}
$$

that is a vector perpendicular to both ${ }_{A} \vec{\Omega}_{B}$ and $\vec{R}_{P}$ according to the right hand rule with a magnitude equal to $R_{E}=\sin (\beta)$ where $\square$ is angle between the two vectors.

The component of the velocity vector in a geocentric reference frame are given by:

$$
\left\{\begin{array}{l}
v_{x}=\Omega_{y} R_{z}-\Omega_{z} R_{y} \\
v_{y}=\Omega_{z} R_{x}-\Omega_{x} R_{z} \\
v_{z}=\Omega_{x} R_{y}-\Omega_{y} R_{z}
\end{array}\right.
$$


Given the previous expression we can compute the velocity in the geocentric coordinate system for every point on the sphere $\vec{R}_{P}$ when we know that the motion is described by the Eulerian vector ${ }_{A} \vec{\Omega}_{B}$. Although the velocity vector is unequivocally determinate by Equation (5), it is not very useful from a practical point of view. The direction of the three axis $x, y$, and $z$, are not immediately identifiable. It would be much more useful if the components of the velocity could be expressed in a local coordinate system. In general, we use a local coordinate system where the directions of the three axes are identified by up direction, the north direction (geographic north), and the east direction. If it is possible to identify three unit vectors $\hat{u}, \hat{n}$, and $\hat{e}$ pointing up, north, and east, then the dot product projects the vector $\vec{v}_{P}$ in those directions.

By definition the up direction is determined by the gravitational field. For a homogeneous sphere it is radially directed from the center of the sphere (the reference of the geocentric coordinate system) to our local position. It is thus directed as the vector $\vec{R}_{P}$. Thus the components of the unit vector $\hat{u}$ in the geocentric reference frame are defined by

$$
\hat{u}=\frac{\vec{R}_{P}}{\left\|\vec{R}_{P}\right\|}=\frac{\vec{R}_{P}}{R_{E}}=\left\{\begin{array}{c}
\mathrm{R}_{x}=\cos \left(\operatorname{Lat}_{P}\right) \cos \left(\operatorname{Lon}_{P}\right) \\
\mathrm{R}_{y}=\cos \left(\text { Lat }_{P}\right) \sin \left(\operatorname{Lon}_{P}\right) \\
\mathrm{R}_{z}=\sin \left(\text { Lat }_{P}\right)
\end{array}\right.
$$

To compute the vector $\hat{e}$ we can take advantage of the fact that it is always tangent to the sphere along an arc of parallel. Since parallel is by definition a small circle associated with the Earth rotation axis (defined by the unit vector $\hat{k}$ directed as the $\mathrm{z}$ axis), the vector $\hat{e}$ must be perpendicular both to the vector $\hat{k}$ and the vector $\vec{R}_{P}$ 
thus the component of the vector $\hat{e}$ in the geocentric reference frame can be expressed as:

$$
\vec{e}=\hat{k} \times \vec{R}_{p}=\left|\begin{array}{ccc}
\hat{\imath} & \hat{\jmath} & \hat{k} \\
k_{x} & k_{y} & k_{z} \\
R_{x}^{P} & R_{y}^{P} & R_{z}^{P}
\end{array}\right|=\left|\begin{array}{ccc}
\hat{\imath} & \hat{\jmath} & \hat{k} \\
0 & 0 & 1 \\
R_{x}^{P} & R_{y}^{P} & R^{\wedge} P_{-} z
\end{array}\right|=-R_{y}^{P} \hat{\imath}+R_{x}^{P} \hat{\jmath}
$$

Given Equation (3) we can rewrite the components of the vector $\vec{e}$ as:

$$
\vec{e}=\left(-\mathrm{R}_{E} \cos \left(\operatorname{Lat}_{P}\right) \sin \left(\operatorname{Lon}_{P}\right), R_{E} \cos \left(\text { Lat }_{P}\right) \cos \left(\operatorname{Lon}_{P}\right), 0\right)
$$

Since $\|e\|^{2}=R_{x}^{P^{2}}+R_{y}^{P^{2}}=R_{E}^{2} \cos ^{2}\left(L a t_{P}\right)$ it is possible to normalize the vector $\vec{e}$ and obtain the unit vector pointing in the local east direction

$$
\hat{e}=\left\{\begin{array}{c}
e_{x}=-\sin \left(\operatorname{Lon}_{P}\right) \\
e_{y}=\cos \left(\operatorname{Lon}_{P}\right) \\
0
\end{array}\right.
$$

To conclude our local coordinate system it is necessary to find the unit vector pointing to the local north. It can easily be computed noting that $\vec{n}=\vec{u} \times \vec{e}$

Thus

(10) $\vec{n}=\left|\begin{array}{ccc}\hat{\imath} & \hat{\jmath} & \hat{k} \\ u_{x} & u_{y} & u_{z} \\ e_{x} & e_{y} & e_{z}\end{array}\right|=\left|\begin{array}{ccc}\hat{\imath} & \hat{\jmath} & \hat{k} \\ R_{x} & R_{y} & R_{z} \\ -R_{y} & R_{x} & 0\end{array}\right|=\left(-R_{x}^{P} R_{z}^{P},-R_{y}^{P} R_{P_{z}}, R_{x}^{P^{2}}+R_{y}^{P^{2}}\right)$

Using Equation (3) and the value of the norm of $\vec{n}$ can be rewritten as

$$
\hat{n}=\left\{\begin{array}{c}
n_{x}=-\sin \left(\operatorname{Lat}_{P}\right) \cos \left(\operatorname{Lon}_{p}\right) \\
n_{y}=-\sin \left(\operatorname{Lat}_{P}\right) \sin \left(\operatorname{Lon}_{p}\right) \\
n_{z}=\cos \left(\text { Lat }_{P}\right)
\end{array}\right.
$$


The local coordinate system can thus be expressed by the three unit vectors

$$
\begin{gathered}
\hat{n}=\left(-\sin \left(\operatorname{Lat}_{P}\right) \cos \left(\operatorname{Lon}_{p}\right),-\sin \left(\operatorname{Lat}_{P}\right) \sin \left(\text { Lon }_{p}\right), \cos \left(\text { Lat }_{P}\right)\right) \\
\hat{e}=\left(-\sin \left(\operatorname{Lon}_{P}\right), \cos \left(\operatorname{Lon}_{P}\right), 0\right) \\
\hat{u}=\left(\cos \left(\text { Lat }_{P}\right) \cos \left(\operatorname{Lon}_{p}\right), \cos \left(\text { Lat }_{P}\right) \sin \left(\text { Lon }_{p}\right), \sin \left(\text { Lat }_{P}\right)\right)
\end{gathered}
$$

The components of $\vec{v}_{P}$ in the local reference frame can thus be written as

$$
\vec{v}_{P}=\left\{\begin{array}{l}
v_{n}=\vec{v}_{P} \cdot \hat{n} \\
v_{e}=\vec{v}_{P} \cdot \hat{e} \\
v_{u}=\vec{v}_{P} \cdot \hat{u}
\end{array}\right.
$$

$\left\{\begin{array}{c}-v_{x} \sin \left(\text { Lat }_{P}\right) \cos \left(\text { Lon }_{p}\right)-v_{y} \sin \left(\text { Lat }_{P}\right) \sin \left(\text { Lon }_{p}\right)+v_{z} \cos \left(\text { Lat }_{P}\right) \\ -v_{x} \sin \left(\text { Lon }_{P}\right)+v_{y} \cos \left(\text { Lon }_{P}\right) \\ 0\end{array}\right.$

The component $v_{u}$ is clearly zero both from a mathematical point of view since $\vec{v}_{p}$ and $\hat{u}$ are perpendicular thus their cross product is null) and for a physical point of view. The Euler vector describe the motion on a sphere, thus the point is not allowed to move neither up nor down.

If we have the observed velocities at multiple point on a rigid plate a combination of Equations (4) and (13) tell us that for each geodetic point the expression

$$
\left\{\begin{array}{c}
v_{n}^{i}=\left(\vec{\Omega} \times \vec{R}^{i}\right) \cdot \hat{n}^{i} \\
v_{e}^{i}=\left(\vec{\Omega} \times \vec{R}^{i}\right) \cdot \hat{e}^{i} \\
v_{u}^{i}=\left(\vec{\Omega} \times \vec{R}^{i}\right) \cdot \hat{u}^{i}=0
\end{array}\right.
$$

where: $\vec{v}^{i}=\left(v_{n}^{i}, v_{e}^{i}\right)$ are the northward and eastward horizontal components of the observed velocity at the point $\mathrm{Pi}_{\mathrm{i}}$ indicated by the vector $\vec{R}^{i} ; \hat{u}, \hat{n}$, and $\hat{e}$ are the unit vector 
defining the local reference frame at the point $\mathrm{P}_{\mathrm{i}}$; and $\vec{\Omega}$ is the Euler vector describing the motion of the rigid plate.

From the combination of cross and dot product of 3 vectors we know that

$$
(\vec{a} \times \vec{b}) \cdot \vec{c}=\vec{a} \cdot(\vec{b} \times \vec{c})
$$

Thus Equation (14) can be rewritten (neglecting the vertical component)

$$
\left\{\begin{array}{l}
v_{n}^{i}=\vec{\Omega} \cdot\left(\vec{R}^{i} \times \hat{n}^{i}\right) \\
v_{e}^{i}=\vec{\Omega} \cdot\left(\vec{R}^{i} \times \hat{e}^{i}\right)
\end{array}\right.
$$

The interesting part of this equation is that the terms $\left(\vec{R}^{i} \times \hat{n}^{i}\right)$ and $\left(\vec{R}^{i} \times \hat{e}^{i}\right)$ are only dependent by the position of the point $P_{i}$ thus the position of the observation point.

If we observe the component of the velocity of the plate with respect to a reference frame (e.g. ITRF), we use Equation (16) to solve for the Euler vector that best describe the observed motion.

For each observation point $\mathrm{P}_{\mathrm{i}}$, Equation (16) can infact be rewritten as

$$
\left\{\begin{array}{l}
v_{n}^{i}=\Omega_{x}\left(\vec{R}^{i} \times \hat{n}^{i}\right)_{x}+\Omega_{y}\left(\vec{R}^{i} \times \hat{n}^{i}\right)_{y}+\Omega_{z}\left(\vec{R}^{i} \times \hat{n}^{i}\right)_{z} \\
v_{e}^{i}=\Omega_{x}\left(\vec{R}^{i} \times \hat{e}^{i}\right)_{x}+\Omega_{y}\left(\vec{R}^{i} \times \hat{e}^{i}\right)_{y}+\Omega_{z}\left(\vec{R}^{i} \times \hat{e}^{i}\right)_{z}
\end{array}\right.
$$

That is a system of 2 equations in 3 unknowns.

In terms of matrices Equation (17) can be rewritten as

$$
\vec{v}=G \vec{\Omega}
$$


Where $\vec{v}=\left(\begin{array}{c}v_{n}^{i} \\ v_{n}^{i}\end{array}\right), \vec{\Omega}=\left(\begin{array}{c}\Omega_{x} \\ \Omega_{y} \\ \Omega_{z}\end{array}\right)$, and $G=\left(\begin{array}{lll}\left(\vec{R}^{i} \times \hat{n}^{i}\right)_{x} & \left(\vec{R}^{i} \times \hat{n}^{i}\right)_{y} & \left(\vec{R}^{i} \times \hat{n}^{i}\right)_{z} \\ \left(\vec{R}^{i} \times \hat{e}^{i}\right)_{x} & \left(\vec{R}^{i} \times \hat{e}^{i}\right)_{y} & \left(\vec{R}^{i} \times \hat{e}^{i}\right)_{z}\end{array}\right)$.

Note again that the matrix $G$ is only dependent on the location of the observation.

In the case more than a single observation is available (for example observations at $\mathrm{N}$ geodetic points), the vectors $\vec{v}$ and $\vec{\Omega}$, and the matrix $G$ can be rewritten:

$$
\vec{v}=\left(\begin{array}{c}
v_{n}^{1} \\
v_{e}^{1} \\
\vdots \\
v_{n}^{i} \\
v_{e}^{i} \\
\vdots \\
v_{n}^{N} \\
v_{e}^{N}
\end{array}\right), \vec{\Omega}=\left(\begin{array}{c}
\Omega_{x} \\
\Omega_{y} \\
\Omega_{z}
\end{array}\right), G=\left(\begin{array}{ccc}
\left(\vec{R}^{1} \times \hat{n}^{1}\right)_{x} & \left(\vec{R}^{1} \times \hat{n}^{1}\right)_{y} & \left(\vec{R}^{1} \times \hat{n}^{1}\right)_{z} \\
\left(\vec{R}^{1} \times \hat{e}^{1}\right)_{x} & \left(\vec{R}^{1} \times \hat{e}^{1}\right)_{y} & \left(\vec{R}^{1} \times \hat{e}^{1}\right)_{z} \\
\vdots & \vdots & \vdots \\
\left(\vec{R}^{i} \times \hat{n}^{i}\right)_{x} & \left(\vec{R}^{i} \times \hat{n}^{i}\right)_{y} & \left(\vec{R}^{i} \times \hat{n}^{i}\right)_{z} \\
\left(\vec{R}^{i} \times \hat{e}^{i}\right)_{x} & \left(\vec{R}^{i} \times \hat{e}^{i}\right)_{y} & \left(\vec{R}^{i} \times \hat{e}^{i}\right)_{z} \\
\vdots & \vdots & \vdots \\
\left(\vec{R}^{N} \times \hat{n}^{N}\right)_{x} & \left(\vec{R}^{N} \times \hat{n}^{N}\right)_{y} & \left(\vec{R}^{N} \times \hat{n}^{N}\right)_{z} \\
\left(\vec{R}^{N} \times \hat{e}^{N}\right)_{x} & \left(\vec{R}^{N} \times \hat{e}^{N}\right)_{y} & \left(\vec{R}^{N} \times \hat{e}^{N}\right)_{z}
\end{array}\right)
$$

With a single observation the system is underdetermined and it does have an infinite number of solution. Already with two observation, the system is over determined and need to be solved in a least square sense (weighted least square would account for the uncertainties associated with the observations). 